\title{
PACAP Induces Light Aversion in Mice by an Inheritable Mechanism Independent of CGRP
}

\author{
Adisa Kuburas, ${ }^{1 *}$ Bianca N. Mason, ${ }^{1,2 *}$ Benjamin Hing, ${ }^{1}$ Anne-Sophie Wattiez, ${ }^{1}$ Alyssa S. Reis, ${ }^{1}$ Levi P. Sowers, ${ }^{1,5}$ \\ Cristina Moldovan Loomis, ${ }^{3}$ Leon F. Garcia-Martinez, ${ }^{3}$ and ${ }^{-}$Andrew F. Russo ${ }^{1,4,5}$ \\ ${ }^{1}$ Department of Molecular Physiology and Biophysics, University of Iowa, Iowa City, Iowa 52242, ${ }^{2}$ Molecular and Cellular Biology Program, \\ University of Iowa, Iowa City, Iowa 52242, ${ }^{3}$ Alder Biopharmaceuticals, Bothell, Washington 98011, ${ }^{4}$ Department of Neurology, University of Iowa, \\ Iowa City, Iowa 52242, and ${ }^{5}$ Center for the Prevention and Treatment of Visual Loss, Veterans Affairs Health Care System, Iowa City, Iowa 52246
}

The neuropeptides CGRP (calcitonin gene-related peptide) and PACAP (pituitary adenylate cyclase-activating polypeptide) have emerged as mediators of migraine, yet the potential overlap of their mechanisms remains unknown. Infusion of PACAP, like CGRP, can cause migraine in people, and both peptides share similar vasodilatory and nociceptive functions. In this study, we have used light aversion in mice as a surrogate for migraine-like photophobia to compare CGRP and PACAP and ask whether CGRP or PACAP actions were dependent on each other. Similar to CGRP, PACAP induced light aversion in outbred CD-1 mice. The light aversion was accompanied by increased resting in the dark, but not anxiety in a light-independent open field assay. Unexpectedly, about one-third of the CD-1 mice did not respond to PACAP, which was not seen with CGRP. The responder and nonresponder phenotypes were stable, inheritable, and not sex linked, although there was a trend for greater responses among male mice. RNA-sequencing analysis of trigeminal ganglia yielded hierarchical clustering of responder and nonresponder mice and revealed a number of candidate genes, including greater expression of the $\operatorname{Trpc} 5$ and Kcnk12 ion channels and glycoprotein hormones and receptors in a subset of male responder mice. Importantly, an antiPACAP monoclonal antibody could block PACAP-induced light aversion but not CGRP-induced light aversion. Conversely, an anti-CGRP antibody could not block PACAP-induced light aversion. Thus, we propose that CGRP and PACAP act by independent convergent pathways that cause a migraine-like symptom in mice.

Key words: CGRP; CGRP antibody; light aversion; migraine; PACAP; PACAP antibody

Significance Statement

The relationship between the neuropeptides CGRP (calcitonin gene-related peptide) and PACAP (pituitary adenylate cyclaseactivating polypeptide) in migraine is relevant given that both peptides can induce migraine in people, yet to date only drugs that target CGRP are available. Using an outbred strain of mice, we were able to show that most, but not all, mice respond to PACAP in a preclinical photophobia assay. Our finding that CGRP and PACAP monoclonal antibodies do not cross-inhibit the other peptide indicates that CGRP and PACAP actions are independent and suggests that PACAP-targeted drugs may be effective in patients who do not respond to CGRP-based therapeutics.

Received Aug. 21, 2020; revised Feb. 26, 2021; accepted Mar. 27, 2021.

Author contributions: A.K., B.N.M., A.-S.W., L.P.S., C.M.L., L.F.G.-M., and A.F.R. designed research; A.K., B.N.M., and A.S.W. performed research; A.K., B.N.M., B.H., A.-S.W., A.S.R., C.M.L., and A.F.R. analyzed data; A.K., B.N.M., B.H., and A.F.R. wrote the paper.

A.F.R. is a consultant for Alder Biopharmaceuticals, Lundbeck, Amgen, Novartis, Eli Lilly, Pharmnovo, Allergan, and Schedule 1 Therapeutics. C.M.L. and L.F.G.-M. were employees of Alder Biopharmaceuticals. The authors declare no other competing financial interests.

This work was supported by the National Institutes of Health Grants NS-098825 (to B.N.M.) and NS-075599 (to A.F.R.), and a grant from Alder Biopharmaceuticals. Additional support was provided by National Institutes of Health/ National Eye Institute Center Support Grant P30-EY-025580 (University of lowa). The contents do not represent the views of the Veterans Administration or the United States Government. We thank Michael Anderson and Kai Wang for help in interpreting the inheritance pattern, and Johannes Ledolter for help with statistical analysis.

B.N. Mason's present address: Brain and Behavior Sciences, Center for Advanced Pain Studies, University of Texas at Dallas, 800 West Campbell Road, Richardson, TX 75080.

*A.K. and B.N.M. contributed equally to this work.

Correspondence should be addressed to at Andrew F. Russo at andrew-russo@uiowa.edu.

https://doi.org/10.1523/JNEUROSCI.2200-20.2021

Copyright $\odot 2021$ the authors

\section{Introduction}

Migraine is a sensory disorder that is more than just a severe headache. It is one of the most incapacitating neurologic disorders in the world (GBD 2016 Headache Collaborators, 2018). One diagnostic criterion for migraine is photophobia, an often debilitating response to normal levels of light (Digre and Brennan, 2012). Despite the high prevalence of migraine and recent advances in treatments, the underlying mechanisms have yet to be fully defined. However, it is now accepted that migraine involves the neuropeptide calcitonin gene-related peptide (CGRP; Russo, 2015; Ashina et al., 2019; Edvinsson, 2019). CGRP is upregulated during migraine attacks (Goadsby and Edvinsson, 1993; Ramón et al., 2017), infusion of CGRP can induce migraine in $\sim 70 \%$ of migraineurs (Lassen et al., 2002), 
and antibodies that block CGRP or its canonical receptor can effectively prevent migraine in $\sim 50 \%$ of patients (Scuteri et al., 2019; Tringali and Navarra, 2019). While key, it is clear that CGRP is not the only player and other sensory peptides have been suggested as candidates (Russo, 2017). In particular, the neuropeptide pituitary adenylate cyclase-activating polypeptide (PACAP) has been linked to migraine pathogenesis (Tuka et al., 2013). Notably, PACAP levels in plasma are increased during migraine attacks, and the infusion of either the PACAP-38 or PACAP-27 isoforms causes migraine in people (Schytz et al., 2009; Tuka et al., 2013; Zagami et al., 2014; Ghanizada et al., 2020).

PACAP shares many functions with CGRP (Kaiser and Russo, 2013). PACAP is a multifunctional neuropeptide involved in nociception, neurogenic inflammation, and neurovascular modulation (Vaudry et al., 2000; Hashimoto et al., 2006). PACAP belongs to the vasoactive intestinal polypeptide (VIP)secretin-glucagon superfamily of neuropeptides (Arimura, 1992). It was first identified as a 38 aa form (PACAP-38; Miyata et al., 1989) and was later found to have a truncated isoform (PACAP-27; Miyata et al., 1990). Both forms have equivalent receptor binding affinities and biological activities (Nilsson et al., 1994). PACAP-38 is the dominant form of the two PACAP peptides, representing $\sim 90 \%$ of the PACAP peptide found in circulation (Arimura et al., 1991). For this reason, we primarily focused on PACAP-38. The actions of PACAP are mediated through activation of a family of G-protein-coupled receptors, as follows: VIP-PACAP1 (VPAC1), VPAC2, PACAP1 (PAC1). PACAP and VIP have equal affinity for VPAC1 and VPAC2, whereas PAC1 is preferentially activated by PACAP (Harmar et al., 2012).

Like CGRP, PACAP and its receptors are found in trigeminal ganglia neurons, but PACAP is found in considerably fewer neurons than CGRP (Frederiksen et al., 2018). Instead, the predominant sites of PACAP and its receptor are in the sphenopalatine ganglia (Uddman et al., 1999; Steinberg et al., 2016), an extracranial parasympathetic ganglion (Khan et al., 2014). Stimulation of sphenopalatine ganglia is likely to contribute to autonomic symptoms of migraine since it can increase cerebral blood flow, intracranial and extracranial vasodilation, and dural plasma protein extravasation (Schoenen, 2015). Interestingly, PACAP can also induce release of CGRP from trigeminal neurons (JansenOlesen et al., 2014), which suggests the possibility of cross talk between the sphenopalatine and trigeminal systems.

To better understand the relationship of PACAP and CGRP in migraine, we have used light-aversive behavior of mice as a surrogate for photophobia (Russo et al., 2009; Kaiser et al., 2012; Mason et al., 2017). In this study, we have demonstrated that peripheral administration of PACAP causes light aversion in outbred CD-1 mice similar to peripheral administration of CGRP (Mason et al., 2017). However, unlike CGRP, PACAP induces light aversion in only a subpopulation of mice and their offspring. The light aversion in the responder population of mice that received PACAP could be attenuated with a monoclonal anti-PACAP antibody (Ab), but not by anti-CGRP antibody. Likewise, light aversion elicited by peripheral CGRP could not be attenuated by an anti-PACAP antibody. These data suggest that PACAP and CGRP can act by distinct pathways that converge downstream of the receptors to cause a migraine-like symptom.

\section{Materials and Methods}

Animals. CD-1 mice were obtained from Charles River. Equivalent numbers of adult male and female mice, $10-20$ weeks of age, were used in all experiments. Mice were housed in groups of three to five per cage, unless otherwise indicated, on a $12 \mathrm{~h}$ light/dark cycle with food and water available ad libitum. All behavioral experiments were performed between 7:00 A.M. and 4:00 P.M. For all experiments, investigators were blinded. Animal procedures were approved by the University of Iowa Animal Care and Use Committee and performed in accordance with the standards set by the National Institutes of Health.

Intraperitoneal drug and antibody administration. Drugs were diluted with Dulbecco's PBS (Hyclone), which was used as the vehicle in all experiments. The amounts injected were as follows: $0.1 \mathrm{mg} / \mathrm{kg}$ rat $\alpha$-CGRP (Sigma-Aldrich), $0.3 \mathrm{mg} / \mathrm{kg}$ PACAP-38 (Bachem), $0.2 \mathrm{mg} / \mathrm{kg}$ PACAP-27 (Bachem), $30 \mathrm{mg} / \mathrm{kg}$ anti-PACAP monoclonal antibody, $30 \mathrm{mg} / \mathrm{kg}$ anti-CGRP monoclonal antibody (ALD405), and $30 \mathrm{mg} / \mathrm{kg}$ monoclonal IgG control antibody. The antibodies were provided by Alder Biopharmaceuticals. The antibody dose corresponded to $8 \mathrm{nmol} /$ mouse, which is approximately threefold excess antibody over exogenous PACAP-38 $(2.6 \mathrm{nmol})$ and eightfold excess over CGRP $(1 \mathrm{nmol})$. Antibody, PACAP, and CGRP were administered at $10 \mu \mathrm{l} / \mathrm{g}$ body weight with a $30 \mathrm{~g} \times 0.5$ inch needle. All injections were performed by either A.K. or B.N.M. Animals were held gently but not anesthetized during injection. After PACAP or CGRP intraperitoneal injection, mice were allowed to recover for $30 \mathrm{~min}$ in their home cages before testing as previously described (Mason et al., 2017). Antibodies were injected intraperitoneally $24 \mathrm{~h}$ before peptide injections.

Light aversion and motility assays. Light/dark boxes with infrared beam tracking were used (Med Associates). CD-1 mice were pre-exposed to the chamber once and $3 \mathrm{~d}$ later were exposed to the light/dark box following treatment. In addition, these mice were tested using bright light (25-27,000 lux), as previously described (Kaiser et al., 2012). Data were collected for $30 \mathrm{~min}$ and analyzed in sequential $5 \mathrm{~min}$ intervals, as well as the average time spent on each side of the chamber per 5 min interval.

Motility outcomes were measured as described previously (Kaiser et al., 2012). To account for the variation in the amount of time mice spent in each zone, data were normalized to time spent in the dark and light zones.

Open field assay. This assay was performed as previously described (Kaiser et al., 2012). Mice were placed in the center of the chamber and tested for $30 \mathrm{~min}$. The periphery was defined as $4.22 \mathrm{~cm}$ from the border, with the remaining $18.56 \times 18.56 \mathrm{~cm}$ area as the center.

RNA-sequencing library preparation and sequencing. Trigeminal ganglia were dissected and flash frozen in liquid nitrogen. Tissue was stored at $-8^{\circ} \mathrm{C}$ until shipping. RNA extraction, library preparation, and sequencing (seq) were performed by Genewiz. Briefly, good quality RNA (RNA integrity number, $\geq 8$ ) was extracted and used for library preparation using poly A selection. Sequencing was performed using Illumina HiSeq with 150 bp paired-end sequencing.

Gene expression, variant identification, and statistical analyses. RNA-seq analysis was performed in-house (B.H.). Gene expression analysis was done using FASTQ files processed using Trim Galore! version 0.5.0 (https://www.bioinformatics.babraham.ac.uk/projects/trim_galore/) to remove Illumina adapters and trimmed to a read length of $149 \mathrm{bp}$ to remove bias bases at the $3^{\prime}$ end. For RNA-seq analysis, postprocessed FASTQ files were aligned to the mouse genome (Gencode M19; GRCm38) using STAR (version 2.6.0a) with -twopassMode Basic option and -sjdbOverhang 148 (Dobin and Gingeras, 2015) with high mapping efficiency of $\sim 93 \%$ giving $\sim 30$ million mapped reads. Alignments were then processed using StringTie (version 1.3.5) for transcript assembly and subsequent quantification of read counts and transcript abundance (Pertea et al., 2016). Data were subsequently imported into R using tximport (version 1.10.1; Soneson et al., 2015) gene level analysis using DESeq2 as described in the vignette (version 1.22.1; Love et al., 2014). Data were analyzed using a negative binomial generalized linear model, whereby gene level counts was the response variable and treatment group was the explanatory variable. Sex was included in the model as a covariate. Since library preparation was performed on all samples at the same time and samples were sequenced together, this eliminated the requirement for controlling for batch effects. The Wald test was used to evaluate statistical difference between treatment groups. The Benjamini-Hochberg procedure was used to adjust $p$ values to 
correct for multiple testing (https://www.statisticshowto.datasciencecentral. $\mathrm{com} /$ benjamini-hochberg-procedure/). Pathway and gene ontology analyses were performed using ConsensusPathDB (Kamburov et al., 2013).

Variant calling and genetic association analysis was performed using the GATK RNA-seq variant calling workflow, as described (https://www.rnaseqblog.com/the-gatk-best-practices-for-variant-calling-on-rnaseq/). Briefly, the STAR 2-pass mapping procedure using regenerated genome workflow was performed using default settings of STAR program with -sjdbOverhang 148 with high mapping efficiency as mentioned above. Read group was assigned followed by subsequent sorting by chromosome, marking of duplicates, and indexing using Picard. Following this, tools from The Genome Analysis Toolkit (GATK; version 3.8-1-0-gf15c1c3ef) were used for subsequent processing. SplitNCigarReads was used to split reads into exon segments, hard-clip sequences that overhang into the intronic regions, and reassign mapping qualities produced by STAR to be compatible with GATK workflow. This was followed by IndelRealigner for local realignment of reads around indels and BaseRecalibrator to detect and adjust systematic errors in base quality scores. Joint genotyping, as previously mentioned (Brouard et al., 2019), was performed using HaplotypeCaller with options -ERC GVCF, dontUseSoftClippedBases and -stand_call_conf 20.0 to produce one gVCF file per sample. GenotypeGVCFs was then used for multisample aggregation to produce a combined variant calling file (McKenna et al., 2010). Given the small sample size, we used a conservative approach whereby only biallelic sites where all samples met previously established thresholds (i.e., Depth of coverage $\geq 10$, Genotype quality $\geq 20$, FisherStrand $<30$, and QualByDepth $\geq 2$ ) were retained for subsequent analysis (https://www.rna-seqblog.com/ the-gatk-best-practices-for-variant-calling-on-rnaseq/; Song et al., 2016). As such, 62,854 sites remained for the study. None of these sites showed significant deviation from Hardy-Weinberg equilibrium after multiple corrections by Bonferroni's method. Genome-wide association analysis was performed using a factored spectrally transformed linear mixed model (FaST-LMM) to estimate and account for genetic relatedness (Lippert et al., 2011). FaSTLMM removed 15,608 sites that were invariant leaving 47,246 sites for the analysis. Correction for multiple testing was performed using Bonferroni. Single nucleotide polymorphism (SNP) sites were annotated using SnpEff which also predicts the impact of those SNPs (Cingolani et al., 2012). The complete RNA-seq data are publicly available on Gene Expression Omnibus (GSE174551).

Quantitative PCR analysis. To further validate the results obtained by RNA-seq, trigeminal ganglia from an independent cohort of mice were used to measure gene expression using real-time quantitative PCR (qPCR) analysis. These mice were purchased $>2$ years after the mice used for the RNA-seq experiments. Primers were designed and validated following a protocol previously described (Walder et al., 2014). The primer sequences are as follows (forward and reverse): Gnrhr: TCTATGATCAGCCTGGCCTG, CATTGCGAGAAGACTGTGGG; Lhb: AGGTATCAAGAATGGAGAGGCT, CCAGAGTTGCGTTGACAGG; Prl: TCATCAATGACTGCCCCACT, GAGGACTGCACCAAACTGAG; $\operatorname{Drd2:}$ GACCACCACCAACTACCTGA, CACCTCCAGATAGACGAC CC; Nts: GAAGATGTGAGAGCCCTGGA, CCGGGCTGTTCACGTT ATTT; Trpc5: TATCATGACCTGGCCAAGCT, GTGTTTTCTCCGC CATCCAG; Kcnk12: GGACTTCCCTGGAGCCTTCT, CCACTGT GGCTGGTGTTGTC; Rest: AGTCTACACCTGCAGCAAGT, GCATG TGTCGCGTTAGATGA; Trpm8: ATTCCGCTGGTGTGCATCTA, GACCTGGTCGTTGTTCTCCT; Tshb: GCCTACTGCCTGACCATCAA, AGACATCCTGAGAGAGTGCA; Cga: TGCTGTCCATGTTCCTGCAT, TGGAGAAGCAACAGCCCATA; Hprt: TCCAACAAAGTCTGGCCT GT, AGCAGTACAGCCCCAAAATG; and Ppia: CAGTGCTCAGA GCTCGAAAG, CCACCGTGTTCTTCGACAT. The PCR products were confirmed by DNA sequencing.

The mRNA levels of genes were determined using Power SYBR Green PCR Master Mix (Applied Biosystems), using protocols previously described and validated (Bohn et al., 2017). Reactions were performed in triplicate using an Applied Biosystems thermocycler (model SDS 7900HT, Thermo Fisher Scientific). Analysis was performed using Applied Biosystems SDS version 2.4 software (Thermo Fisher Scientific). The Ct values were normalized to the geometric mean of Hprt and Ppia using the $2^{-(\Delta \mathrm{Ct})}$ method. Results reported as box graphs (median, first, and third quartile) and whiskers (maximum and minimum) are separated by sex.One nonresponder mouse was excluded from the analysis because some of the no-reverse transcriptase controls yielded low expression, indicating potential contamination.

Experimental design and statistical analyses. Each experiment was conducted separately with a new cohort of mice, except that mice used in the open field assay were previously tested for light aversion. For light aversion experiments, data are expressed as the time spent in the light as a function of time in the $30 \mathrm{~min}$ assay with the average for each cohort per $5 \mathrm{~min}$ interval (line graph) and as the average time per $5 \mathrm{~min}$ over the entire $30 \mathrm{~min}$ assay for each individual mouse (scatter plot). For open field experiments, data are expressed as the percentage of time the mouse spent in the center zone for the entire $30 \mathrm{~min}$ duration of the assay. For resting time, rearing (vertical beam breaks), and transitions, data are represented in the same way as the light aversion assay, except normalized to the time spent in light and dark zones for resting and rearing. Individual numbers of animals used for each experiment can be found in the legend of each figure. For these studies, 1017 mice were tested, 13 of which were excluded for reasons described below. Hence, data are from a total of 1004 mice ( 504 female, 500 male).

A two-way, repeated-measures ANOVA (factors: treatment and observation time) was used for data plotted as a function of time. A oneway ANOVA was used to determine whether overall significant effects were observed in bar graphs with individual points. A Bonferroni multiple-comparisons test was used as the post hoc analysis. Data are reported as the mean \pm SEM. Data were analyzed using GraphPad Prism 8 version 8.4.1 software. Significance was set at $p<0.05$ for all analyses. G power was used to perform a power analysis. Expected effect sizes were based on previously published light aversion data with CGRP (Mason et al., 2017). All sample sizes for light aversion were greater than or equal to the suggested sample size of 9 calculated in G power for a 0.8 desired power. Exclusions were applied to the dataset from the pre-exposure data (before treatments) for the following reasons: never leaving the light zone, an overall resting time $>90 \%$, and spending 1 SD less time in the light than the average baseline of the entire cohort tested on that day. Exclusions were also applied to the dataset after treatment for the following reasons: never leaving the light zone during $30 \mathrm{~min}$ of testing, an overall resting time of $>90 \%$, and statistical outliers according to the GraphPad Prism ROUT method $(\mathrm{Q}=1 \%)$. A total of 12 of 881 mice post-treatment were excluded, 11 for $>90 \%$ resting time and 1 as a statistical outlier. All behavioral statistics are reported in Table 1 and Extended Data Table 1-1. All data are available on request.

\section{Results}

\section{PACAP-38-induced light aversion in CD-1 mice}

We have previously shown that peripheral administration of CGRP causes light aversion in CD-1 mice (Mason et al., 2017). Here we investigated whether PACAP-38 can elicit light aversion similar to CGRP. CD-1 mice were given vehicle, PACAP-38, or CGRP in a single intraperitoneal injection and tested $30 \mathrm{~min}$ postinjection. When we looked at light aversion as a function of time over the $30 \mathrm{~min}$ testing period, there was a significant treatment effect (Fig. 1A). PACAP induced light aversion comparable to that with CGRP. Both PACAP- and CGRP-treated mice spent significantly less time in light compared with vehicle-treated mice (Fig. 1B, left). On average, the vehicle-treated mice spent $100 \mathrm{~s}$ in the light per $5 \mathrm{~min}$ interval compared with $55 \mathrm{~s}$ for PACAP-treated mice and $34 \mathrm{~s}$ for CGRP-treated animals (Fig. $1 B$, left). Since both male and female mice were tested, we looked to see whether there was any difference between sexes (Fig. $1 B$, right). There is a trend toward males spending less time in light, but it is not significantly different from that in females. Power analysis predicts that we would need $n=100$ mice of each sex to see a significant difference. Interestingly, with CGRP, although not statistically significant, we see an opposite trend with females spending less time in the light, as previously reported in the study by Mason et al. (2017). The paradigm of two pre-exposures 
Table 1. Statistical analyses

\begin{tabular}{cl}
\hline Figure & \multicolumn{1}{c}{ Analysis } \\
\hline Figure 1A & Two-way repeated-measures ANO \\
& Interaction factor \\
& Tx(****) Treatment factor \\
& Time factor \\
Figure 1B & One-way ANOVA for treatment \\
Left panel & Bonferroni's multiple comparisons \\
& Veh vs CGRP \\
& Veh vs P-38 \\
& CGRP vs P-38 \\
Figure 1B & One-way ANOVA for treatment \\
Right panel & Bonferroni's multiple comparisons \\
& F Veh vs M Veh \\
& F Veh vs F CGRP \\
& F Veh vs F P-38 \\
& M Veh vs M CGRP \\
& M Veh vs M P-38 \\
& F CGRP vs M CGRP \\
& F P-38 vs M P-38
\end{tabular}

Figure $1 C$ One-way ANOVA for treatment Bonferroni's multiple comparisons Veh vs CGRP

Veh vs $P-38$

CGRP vs P-38

Figure 1D One-way ANOVA for treatment Bonferroni's multiple comparisons Veh vs CGRP

Veh vs $\mathrm{P}-38$

CGRP vs P-38

Figure $2 A \quad$ Two-way repeated-measures ANOVA

Left panel

Dark zone

Interaction factor

$\left.\mathrm{Tx}{ }^{* * * *}\right)$ Treatment factor

Time factor

Figure $2 A \quad$ One-way ANOVA for treatment

Right panel Bonferroni's multiple comparisons

Dark zone

Veh vs CGRP

Veh vs $P-38$

CGRP vs $P-38$

Figure $2 A \quad$ Two-way mixed-model ANOVA

Left panel Interaction factor

Light zone

TxTreatment factor

Time factor

Figure $2 A \quad$ One-way ANOVA for treatment

Right panel Bonferroni's multiple comparisons

Light zone

Figure $2 B$

Left panel

Dark zone

Veh vs CGRP

Veh vs $\mathrm{P}-38$

CGRP vs P-38

Two-way repeated measure ANOVA Interaction factor

$\mathrm{Tx}\left({ }^{* * * *}\right)$ Treatment factor

Time factor

Figure $2 B \quad$ One-way ANOVA for treatment

Right panel Bonferroni's multiple comparisons

Dark zone Veh vs CGRP

Veh vs $P-38$

CGRP vs $P-38$

Figure $2 B \quad$ Two-way Mixed model ANOVA

Left panel Interaction factor

Light zone $\left.\quad \mathrm{Tx}^{(* *}\right)$ Treatment factor

Time factor

Figure $2 B$

Right panel

One-way ANOVA for treatment

Light zone
Statistics (symbol on figure)

$F_{(10,340)}=1.091, p=0.3680$

$F_{(2,68)}=14.40, p<0.0001$

$F_{(3.495,237.6)}=2.522, p=0.0495$

$F_{(2,68)}=14.40, p<0.0001$

$p<0.00011^{(* * *)}$

$p=0.0010(\wedge \wedge \wedge)$

$p>0.9999$

$F_{(5,65)}=7.028, p<0.0001$

$p>0.9999$

$p=0.0090(* *)$

$p \geq 0.9999$

$p=0.0050$ (\#\#)

$p=0.0020(\wedge \wedge)$

$p>0.9999$

$p=0.5916$

$F_{(2,60)}=12.70, p<0.0001$

$p<0.0001^{(* * * *)}$

$p=0.0025(\wedge \wedge)$

$p=0.1229$

$F_{(2,53)}=0.5471, p=0.5818$

$p>0.9999$

$p=0.9050$

$p>0.9999$

$F_{(10,340)}=1.306, p=0.2254$

$F_{(2,68)}=21.14, p<0.0001$

$F_{(4.034,274.3)}=36.73, p<0.0001$

$F_{(2,68)}=21.14, p<0.0001$

$p<0.00011^{(* * *)}$

$p<0.0001(\wedge \wedge \wedge \wedge)$

$p=0.3288$

$F_{(10,253)}=1.377, p=0.1913$

$F_{(2,68)}=0.7043, p=0.4980$

$F_{(3.998,202.3)}=30.37, p<0.0001$

$F_{(2,68)}=0.1685, p=0.8453$

$p>0.9999$

$p>0.9999$

$p>0.9999$

$F_{(10,340)}=2.231, p=0.0158$

$F_{(2,68)}=15.75, p<0.0001$

$F_{(4.168,283.4)}=15.20, p<0.0001$

$F_{(2,68)}=15.75, p<0.0001$

$p<0.0001\left(^{* * * *}\right)$

$p=0.0006(\wedge \wedge \wedge)$

$p=0.2939$

$F_{(10,252)}=3.086, p=0.0010$

$F_{(2,68)}=5.921, p=0.0043$

$F_{(4.562,229.9)}=1.072, p=0.3746$

$F_{(2,68)}=7.204, p=0.0015$

$p=0.0010\left(^{* * *}\right)$

$p=0.2557$

$p=0.1046$

(Table continues.)
Table 1 Continued

\begin{tabular}{|c|c|c|}
\hline Figure & Analysis & Statistics (symbol on figure) \\
\hline Figure $2 C$ & Two-way repeated-measures ANOVA & \\
\hline \multirow[t]{3}{*}{ Left panel } & Interaction factor & $F_{(10,340)}=1.401, p=0.1780$ \\
\hline & $\mathrm{Tx}\left({ }^{* * * *}\right)$ Treatment factor & $F_{(2,68)}=20.19, p<0.0001$ \\
\hline & Time factor & $F_{(3.752,255.1)}=16.97, p<0.0001$ \\
\hline \multirow{5}{*}{$\begin{array}{l}\text { Figure } 2 C \\
\text { Right panel }\end{array}$} & One-way ANOVA for treatment & $F_{(2,68)}=20.19, p<0.0001$ \\
\hline & Bonferroni's multiple comparisons & \\
\hline & Veh vs CGRP & $\left.p<0.00011^{* * * *}\right)$ \\
\hline & Veh vs $\mathrm{P}-38$ & $p=0.0006(\wedge \wedge \wedge)$ \\
\hline & CGRP vs P-38 & $p=0.0388(\#)$ \\
\hline Figure $3 A$ & Two-way repeated-measures ANOVA & \\
\hline \multirow[t]{6}{*}{ Left panel } & Interaction factor & $F_{(10,275)}=1.203, p=0.2890$ \\
\hline & Tx1 $\left.{ }^{* * * *}\right)$ Treatment factor & $F_{(2,55)}=38.19, p<0.0001$ \\
\hline & Time factor & $F_{(3.957,217.7)}=2.872, p=0.0244$ \\
\hline & Interaction factor & $F_{(10,275)}=1.375, p=0.1917$ \\
\hline & Tx2(****) Treatment factor & $F_{(2,55)}=12.48, p<0.0001$ \\
\hline & Time factor & $F_{(3.958,217.7)}=2.872, p=0.0030$ \\
\hline Figure $3 A$ & One-way ANOVA for treatment & $F_{(2,55)}=38.19, p<0.0001$ \\
\hline Right panel & Bonferroni's multiple comparisons & \\
\hline \multirow[t]{3}{*}{$\mathrm{Tx} 1$} & Veh vs $P-38 R$ & $p<0.0001\left(^{* * * *}\right)$ \\
\hline & Veh vs $\mathrm{P}-38 \mathrm{~N}$ & $p=0.3359$ \\
\hline & $\mathrm{P}-38 \mathrm{R}$ vs $\mathrm{P}-38 \mathrm{~N}$ & $p<0.0001(\wedge \wedge \wedge \wedge)$ \\
\hline Figure $3 A$ & One-way ANOVA for treatment & $F_{(2,55)}=12.48, p<0.0001$ \\
\hline Right panel & Bonferroni's multiple comparisons & \\
\hline \multirow[t]{3}{*}{$\mathrm{Tx} 2$} & Veh vs $P-38 R$ & $p=0.0013\left({ }^{* *}\right)$ \\
\hline & Veh vs $\mathrm{P}-38 \mathrm{~N}$ & $p=0.5303$ \\
\hline & $\mathrm{P}-38 \mathrm{R}$ vs $\mathrm{P}-38 \mathrm{~N}$ & $p<0.0001(\wedge \wedge \wedge \wedge)$ \\
\hline \multirow{11}{*}{$\begin{array}{l}\text { Figure } 3 B \\
\text { Tx1 }\end{array}$} & One-way ANOVA for treatment & $F_{(5,52)}=14.72, p<0.0001$ \\
\hline & Bonferroni's multiple comparisons & \\
\hline & F Veh vs M Veh & $p>0.9999$ \\
\hline & F Veh vs F P-38 R & $\left.p=0.0012{ }^{(* *}\right)$ \\
\hline & F Veh vs $F-38 \mathrm{~N}$ & $p>0.9999$ \\
\hline & F P-38 R vs F P-38 N & $p<0.0001(\wedge \wedge \wedge \wedge)$ \\
\hline & $M$ Veh vs M P-38 R & $p<0.0001$ (\#\#\#) \\
\hline & M Veh vs M P-38 N & $p>0.9999$ \\
\hline & M P-38 R vs M P-38 N & $p<0.0001$ (\&\&\&\&) \\
\hline & F P-38 R vs M P-38 R & $p>0.9999$ \\
\hline & F P-38 N vs M P-38 N & $p>0.9999$ \\
\hline \multirow{11}{*}{$\begin{array}{l}\text { Figure } 3 B \\
\text { Tx2 }\end{array}$} & One-way ANOVA for treatment & $F_{(5,52)}=6.190, p=0.0001$ \\
\hline & Bonferroni's multiple comparisons & \\
\hline & F Veh vs M Veh & $p>0.9999$ \\
\hline & F Veh vs F P-38 R & $p>0.9999$ \\
\hline & F Veh vs F P-38 N & $p=0.8740$ \\
\hline & F P-38 R vs F P-38 N & $p=0.0301(\wedge)$ \\
\hline & $M$ Veh vs M P-38 R & $p=0.0024$ \\
\hline & M Veh vs M P-38 N & $p>0.9999$ \\
\hline & M P-38 R vs M P-38 N & $p=0.0142(\&)$ \\
\hline & F P-38 R vs M P-38 R & $p>0.9999$ \\
\hline & F $P-38 N$ vs $M P-38 N$ & $p>0.9999$ \\
\hline \multirow[t]{7}{*}{ Figure $4 A$} & Two-way repeated-measures ANOVA & \\
\hline & Interaction factor & $F_{(25,1115)}=1.358, p=0.1124$ \\
\hline & $\left.\operatorname{Tx} 1{ }^{* * * *}\right)$ Treatment factor & $F_{(5,223)}=18.94, p<0.0001$ \\
\hline & Time factor & $F_{(4.377,976.1)}=15.73, p<0.0001$ \\
\hline & Interaction factor & $F_{(25,1045)}=2.409, p<0.0001$ \\
\hline & Tx2 $\left.{ }^{(* * *)}\right)$ Treatment factor & $F_{(5,209)}=19.68, p<0.0001$ \\
\hline & Time factor & $F_{(4.117,860.4)}=14.83, p<0.0001$ \\
\hline \multirow{7}{*}{$\begin{array}{l}\text { Figure } 4 B \\
\text { Tx1 }\end{array}$} & One-way ANOVA for treatment & $F_{(5,223)}=18.94, p<0.0001$ \\
\hline & Bonferroni's multiple comparisons & \\
\hline & RxR Veh vs P-38 & $\left.p<0.0001{ }^{* * * *}\right)$ \\
\hline & RxN Veh vs P-38 & $p<0.0001(\wedge \wedge \wedge \wedge)$ \\
\hline & NxN Veh vs $\mathrm{P}-38$ & $p>0.9999$ \\
\hline & RxR P-38 vs NxN P-38 & $p<0.0001$ (\#\#\#\#) \\
\hline & RxN P-38 vs NxN P-38 & $p<0.0001$ (\&\&\&\&) \\
\hline Figure $4 B$ & One-way ANOVA for treatment & $F_{(5,209)}=19.68, p<0.0001$ \\
\hline
\end{tabular}

Tx2
Tx1(****) Treatment factor

Tx2 $\left.{ }^{* * * *}\right)$ Treatment factor

P-38 R vs P-38

Right panel Bonferroni's multiple comparisons

$F$ Veh vs $M$ Veh

F P-38 R vs F P-38

$F P-38 R$ vs $M P-38 R$

Bonferroni's multiple comparisons

Veh vs $M$ Veh

P-38 R v F P -38

$M$ Veh vs $M P-38 R$

eh vs $M P-38 \mathrm{~N}$

Interaction factor

x1 $1(* * *)$ Treatment factor

Interaction factor

Tx2(****) Treatment factor

Bonferroni's multiple comparisons

RxR Veh vs P-38

vs $P-38$

RxR P-38 vs NxN P-38

One-way ANOVA for treatment

Bonferroni's multiple comparisons
$=0.1780$

$F_{(3.752,255.1)}=16.97, p<0.0001$

$p<0.0001\left(^{* * * *}\right)$

$p=0.0006(\wedge \wedge \wedge)$

$F_{(10,275)}=1.203, p=0.2890$

$F_{(3.957,217.7)}=2.872, p=0.0244$

$F_{(3.958,217.7)}=2.872, p=0.0030$

$p<0.0001(* * * *)$

$p=0.3359$

$p=0.0013(* *)$

$0001(\wedge \wedge \wedge \wedge)$

$p>0.9999$

$p<0.0001(\wedge \wedge \wedge \wedge)$

$p<0.0001$ (\#\#\#\#)

$p>0.9999$

$p>0.9999$

$p>0.9999$

$p>0.9999$

$p=0.0024$ (\#\#)

$p>0.9999$

$F_{(25,1115)}=1.358, p=0.1124$

$F_{(5,223)}=18.94, p<0.0001$

$F_{(5,209)}=19.68, p<0.0001$

$F_{(4.117,860.4)}=14.83, p<0.000$

$p<0.0001(* * * *)$

$p<0.0001(\wedge \wedge \wedge \wedge)$

$F_{(5,209)}=19.68, p<0.0001$

(Table continues.)
Veh vs CGRP

Veh vs $P$-38

CGRP vs $P-38$ 
Table 1 Continued

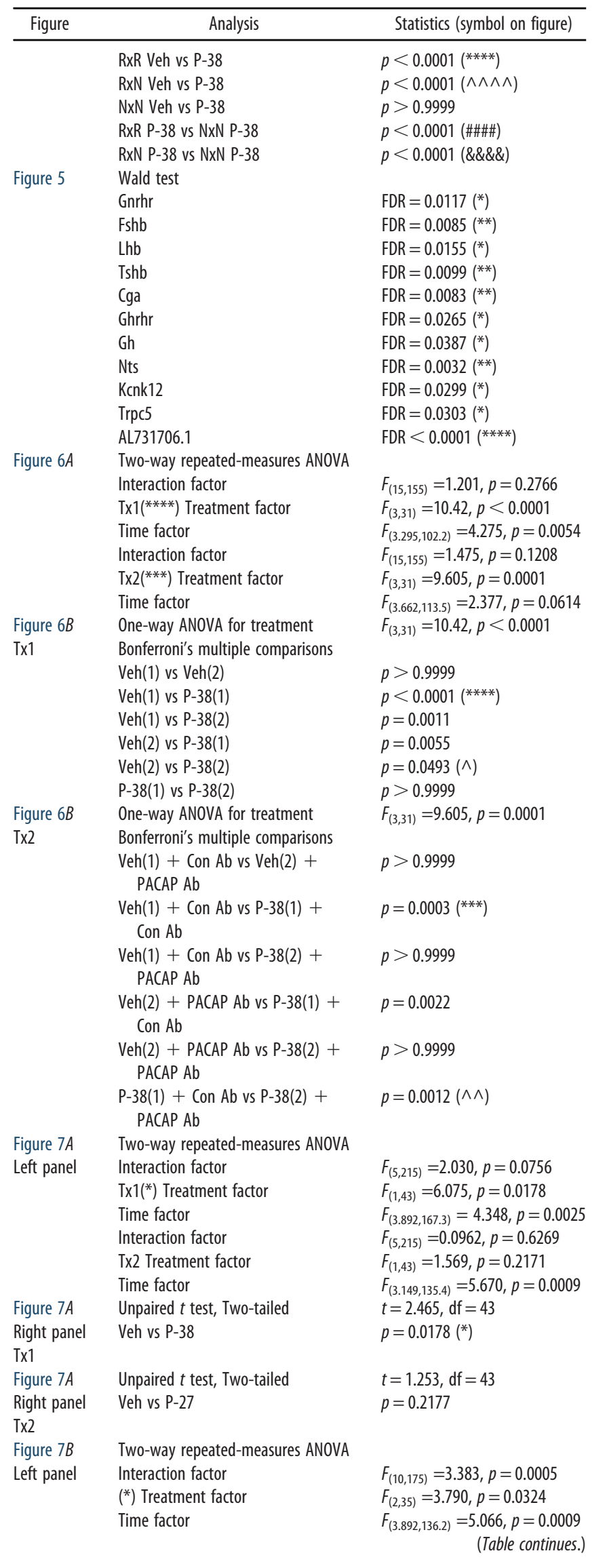

Table 1 Continued

\begin{tabular}{|c|c|c|}
\hline Figure & Analysis & Statistics (symbol on figure) \\
\hline \multirow[t]{4}{*}{$\begin{array}{l}\text { Figure } 7 B \\
\text { Right panel }\end{array}$} & $\begin{array}{l}\text { One-way ANOVA for treatment } \\
\text { Bonferroni's multiple comparisons }\end{array}$ & $F_{(2,35)}=12.11, p=0.0001$ \\
\hline & Veh vs $P-38$ & $p=0.0002\left({ }^{* * *}\right)$ \\
\hline & Veh vs $\mathrm{P}-27$ & $p=0.0007(\wedge \wedge \wedge)$ \\
\hline & $\mathrm{P}-38$ vs $\mathrm{P}-27$ & $p>0.9999$ \\
\hline \multirow[t]{7}{*}{ Figure $7 C$} & Two-way repeated-measures ANOVA & \\
\hline & Interaction factor & $F_{(15,210)}=3.895, p<0.0001$ \\
\hline & Tx1 ${ }^{(* * *)}$ Treatment factor & $F_{(3,42)}=10.83, p<0.0001$ \\
\hline & Time factor & $F_{(3.629,152.4)}=2.058, p=0.0957$ \\
\hline & Interaction factor & $F_{(15,210)}=4.186, p<0.0001$ \\
\hline & Tx2 Treatment factor & $F_{(3,42)}=1.808, p=0.1603$ \\
\hline & Time factor & $F_{(3.081,129.4)}=7.813, p<0.0001$ \\
\hline \multirow[t]{7}{*}{$\begin{array}{l}\text { Figure } 7 D \\
\mathrm{Tx} 1\end{array}$} & $\begin{array}{l}\text { One-way ANOVA for treatment } \\
\text { Bonferroni's multiple comparisons }\end{array}$ & $F_{(3,42)}=36.91, p<0.0001$ \\
\hline & Veh(1) vs Veh(2) & $p>0.9999$ \\
\hline & Veh(1) vs $\mathrm{P}-27(1)$ & $\left.p<0.0001{ }^{* * * *}\right)$ \\
\hline & $\operatorname{Veh}(1)$ vs $\mathrm{P}-27(2)$ & $p<0.0001$ \\
\hline & $\operatorname{Veh}(2)$ vs $\mathrm{P}-27(1)$ & $p<0.0001$ \\
\hline & $\operatorname{Veh}(2)$ vs $P-27(2)$ & $p<0.0001(\wedge \wedge \wedge \wedge)$ \\
\hline & $\mathrm{P}-27(1)$ vs $\mathrm{P}-27(2)$ & $p>0.9999$ \\
\hline \multirow[t]{7}{*}{$\begin{array}{l}\text { Figure 7D } \\
\text { Tx2 }\end{array}$} & $\begin{array}{l}\text { One-way ANOVA for treatment } \\
\text { Bonferroni's multiple comparisons }\end{array}$ & $F_{(3,42)}=10.84, p<0.0001$ \\
\hline & $\begin{array}{l}\text { Veh(1) + Con Ab vs Veh(2) + } \\
\text { PACAP Ab }\end{array}$ & $p>0.9999$ \\
\hline & $\begin{array}{l}\text { Veh(1) }+ \text { Con Ab vs P-27(1) }+ \\
\quad \text { Con Ab }\end{array}$ & $p=0.0045\left(^{* *}\right)$ \\
\hline & $\begin{array}{l}\text { Veh(1) + Con Ab vs P-27(2) + } \\
\text { PACAP Ab }\end{array}$ & $p>0.9999$ \\
\hline & $\begin{array}{l}\text { Veh(2) + PACAP Ab vs P-27(1) + } \\
\quad \text { Con Ab }\end{array}$ & $p=0.0002$ \\
\hline & $\begin{array}{l}\text { Veh(2) + PACAP Ab vs P-27(2) + } \\
\text { PACAP Ab }\end{array}$ & $p>0.9999$ \\
\hline & P-27(1) + Con Ab vs P-27(2) + & $p<0.0001(\wedge \wedge \wedge \wedge)$ \\
\hline
\end{tabular}

Figure $8 A \quad$ Two-way repeated-measures ANOVA Interaction factor

$\left.\mathrm{Tx} 1{ }^{* * * *}\right)$ Treatment factor

Time factor

Interaction factor

Tx2 ${ }^{(* * *)}$ Treatment factor

Time factor

Figure $8 B \quad$ One-way ANOVA for treatment

Tx1 Bonferroni's multiple comparisons

Veh(1) vs Veh(2)

Veh(1) vs CGRP(1)

Veh(1) vs CGRP(2)

Veh(2) vs CGRP(1)

Veh(2) vs CGRP(2)

CGRP(1) vs CGRP(2)

Figure $8 B \quad$ One-way ANOVA for treatment

Tx2 Bonferroni's multiple comparisons

Veh(1) + Con Ab vs Veh(2) +

PACAP Ab

Veh(1) + Con Ab vs CGRP(1) + Con $\mathrm{Ab}$

Veh(1) + Con Ab vs CGRP(2) + PACAP Ab

Veh(2) + PACAP Ab vs CGRP(1) + Con $\mathrm{Ab}$

Veh(2) + PACAP Ab vs $(G R P(2)+p<0.0001(\wedge \wedge \wedge \wedge)$

PACAP Ab

CGRP(1) + Con Ab vs GGRP(2) $+\quad p>0.9999$ PACAP Ab

$$
\begin{aligned}
& F_{(15,485)}=2.660, p=0.0007 \\
& F_{(3,97)}=43.78, p<0.0001 \\
& F_{(4.332,420.2)}=3.336, p=0.0086 \\
& F_{(15,485)}=1.735, p=0.0414 \\
& F_{(3,97)}=17.71, p<0.0001 \\
& F_{(3.920,380.2)}=5.455, p=0.0003 \\
& F_{(3,97)}=43.78, p<0.0001 \\
& p>0.9999 \\
& p<0.0001\left(^{* * * *)}\right. \\
& p<0.0001 \\
& p<0.0001 \\
& p<0.0001(\wedge \wedge \wedge \wedge) \\
& p>0.9999 \\
& F_{(3,97)}=17.71, p<0.0001 \\
& p=0.7674 \\
& p=0.0002(* * *) \\
& p=0.0007 \\
& p<0.0001 \\
& p<0.0001(\wedge \wedge \wedge \wedge) \\
& p>0.9999
\end{aligned}
$$


Table 1 Continued

\begin{tabular}{|c|c|c|}
\hline Figure & Analysis & Statistics (symbol on figure) \\
\hline \multirow[t]{7}{*}{ Figure $9 A$} & Two-way repeated-measures ANOVA & \\
\hline & Interaction factor & $F_{(15,530)}=2.608, p=0.0008$ \\
\hline & $\operatorname{Tx} 11^{(* * *)}$ Treatment factor & $F_{(3,106)}=26.07, p<0.0001$ \\
\hline & Time factor & $F_{(4.489,475.8)}=21.75, p<0.0001$ \\
\hline & Interaction factor & $F_{(15,530)}=0.4614, p=0.9588$ \\
\hline & $\operatorname{Tx2}(* * *)$ Treatment factor & $F_{(3,106)}=15.93, p<0.0001$ \\
\hline & Time factor & $F_{(4.036,427.9)}=7.364, p<0.0001$ \\
\hline \multirow{8}{*}{$\begin{array}{l}\text { Figure } 9 B \\
T \times 1\end{array}$} & One-way ANOVA for treatment & $F_{(3,106)}=26.07, p<0.0001$ \\
\hline & Bonferroni's multiple comparisons & \\
\hline & $\operatorname{Veh}(1)$ vs Veh(2) & $p>0.9999$ \\
\hline & Veh(1) vs $\mathrm{P}-38(1)$ & $\left.p<0.00011^{* * * *}\right)$ \\
\hline & $\operatorname{Veh}(1)$ vs $\mathrm{P}-38(2)$ & $p<0.0001$ \\
\hline & $\operatorname{Veh}(2)$ vs $\mathrm{P}-38(1)$ & $p<0.0001$ \\
\hline & Veh(2) vs $P-38(2)$ & $p<0.0001(\wedge \wedge \wedge \wedge)$ \\
\hline & $\mathrm{P}-38(1)$ vs $\mathrm{P}-38(2)$ & $p>0.9999$ \\
\hline \multirow{8}{*}{$\begin{array}{l}\text { Figure } 9 B \\
T \times 2\end{array}$} & One-way ANOVA for treatment & $F_{(3,106)}=15.93, p<0.0001$ \\
\hline & Bonferroni's multiple comparisons & \\
\hline & $\begin{array}{l}\operatorname{Veh}(1)+\text { Con Ab vs Veh(2) + } \\
\quad \text { CGRP Ab }\end{array}$ & $p>0.9999$ \\
\hline & $\begin{array}{l}\text { Veh(1) }+ \text { Con Ab vs P-38(1) + } \\
\quad \text { Con Ab }\end{array}$ & $\left.p<0.0001{ }^{* * * *}\right)$ \\
\hline & $\begin{array}{l}\text { Veh(1) + Con Ab vs P-38(2) + } \\
\quad \text { CGRP Ab }\end{array}$ & $p<0.0001$ \\
\hline & $\begin{array}{l}\text { Veh(2) }+ \text { CGRP Ab vs P-38(1) }+ \\
\quad \text { Con Ab }\end{array}$ & $p<0.0001$ \\
\hline & $\begin{array}{l}\text { Veh(2) }+ \text { CGRP Ab vs P-38(2) + } \\
\quad \text { CGRP Ab }\end{array}$ & $p=0.0001(\wedge \wedge \wedge)$ \\
\hline & $\begin{array}{l}\text { P-38(1) + Con Ab vs P-38(2) + } \\
\quad \text { CGRP Ab }\end{array}$ & $p>0.9999$ \\
\hline
\end{tabular}

Analyses are described for each figure. Statistical analyses for extended data are described in Extended Data Table 1-1.

to the chamber to reduce the exploratory drive was originally developed with C57BL/6J mice (Kaiser et al., 2012). Our previous data suggested that CD-1 mice are more sensitive to CGRP than C57BL/6J mice (Mason et al., 2017), so we asked whether only one pre-exposure was sufficient to detect PACAP- and CGRP-induced light aversion in CD-1 mice. After only one pre-exposure to the chamber, mice treated with PACAP or CGRP spent significantly less time in light compared with vehicle-treated mice (Fig. 1C). All subsequent studies used just a single pre-exposure.

To test whether the light aversion was because of an anxietylike response, we tested mice in a light-independent open field assay. As with the light aversion assay, mice were tested $30 \mathrm{~min}$ after injection of PACAP-38, CGRP, or vehicle. There was no significant difference in the time the mice spent in the center of the open field between vehicle and PACAP-38- or CGRP-treated animals (Fig. 1D).

We then asked whether PACAP-38 induces light aversion at later time points. The mice were first tested at $30 \mathrm{~min}$ postinjection to confirm PACAP-induced light aversion. Both male and female PACAP-treated mice spent significantly less time in light compared with vehicle-treated mice (Extended Data Fig. 1-1). As seen in the previous experiments, there was a trend toward male mice spending less time in the light but it was not significant. Three days later, those same mice were tested at $60 \mathrm{~min}$ postinjection. At this later time, there was no significant difference between PACAP-treated and vehicle-treated mice. There was also no difference between male and female mice (Extended Data Fig. 1-1).

PACAP-38 reduces motility in the dark zone

To see whether PACAP has the same effect on motility as CGRP (Kaiser et al., 2012; Mason et al., 2017), we looked at resting time, rearing (vertical beam brakes), and transitions. Motility was measured at the same time from the same mice as during the light aversion experiment shown in Figure 1A. PACAP-38 increased resting in the dark zone, but not in the light, similar to CGRP (Fig. 2A). Rearing behavior was also significantly decreased by PACAP-38 in the dark zone, but not the light zone (Fig. 2B). CGRP also decreased rearing, but the decrease was significant in both the light and dark zones, as previously reported for C57BL/6J mice (Mason et al., 2017). The number of transitions between the light and dark zones was significantly decreased in both PACAP-38- and CGRP-treated mice compared with vehicle (Fig. 2C). We also asked whether there was a correlation between the time spent in light and the motility parameters (Extended Data Fig. 2-1). There was a moderate correlation between the time spent in the light and the amount of time resting in the dark, regardless of treatment. For the resting time in the light, there was a weak correlation after CGRP and PACAP treatment, but little if any correlation after vehicle treatment. There was also a moderate correlation for rearing in dark for all treatments, while only a weak correlation for rearing in light only for CGRP and PACAP treatments. We also saw a moderate correlation for transitions after CGRP and PACAP treatment. Thus, mice that spent less time in the light also rest more in the dark, rear less, and have fewer transitions between the zones.

\section{Two subpopulations identified in CD-1 mice: PACAP-38 responders and nonresponders}

In all experiments, we noticed that about one-third of CD-1 mice treated with PACAP-38 did not appear to have a light aversive response. This was not seen with parallel treatments with CGRP or in previous CGRP studies (Mason et al., 2017). To explore the possibility that there might be two subpopulations in this outbred strain, we tested all the mice again after a second injection of PACAP (Fig. 3A). Responders were defined as mice with time in light 1 SD below the group baseline average. Mice with time in light above that were considered nonresponders. The two phenotypes were represented in both sexes (Fig. 3B), but there was a significantly higher percentage of nonresponders in female mice (Extended Data Fig. 3-1). Of the mice that were light aversive after the first injection of PACAP, 89\% were also light aversive after the second injection of PACAP (Fig. 3C). Likewise, of the mice that were not light aversive after the first injection, $85 \%$ were still not light aversive after the second injection. For comparison, using the same criteria for the vehicle treatments, $20 \%$ would have been classified as "responders" after the first vehicle treatment, and $30 \%$ after the second treatment. Given this variability among the mice, we asked whether mice that showed a vehicle response were the same mice that were PACAP responders. Not surprisingly, mice that preferred to be in the dark in response to vehicle injection also preferred to be in the dark following PACAP injection, but there was still a significantly greater time in the dark following PACAP injection (Extended Data Fig. 3-2).

In addition to light aversion, we also looked at the motility parameters of resting, rearing, and transitions in the responder and nonresponder populations. The responder population had increased resting in the dark only (Extended Data Fig. 3-3A), as observed without separating the two groups (Fig. 2A). There was also decreased rearing in the dark for the responders, which was also now significantly decreased in the light (Extended Data Fig. 3$3 B)$. Finally, the responder population had decreased transitions (Extended Data Fig. 3-3C). In contrast, there was no change in any of these parameters in nonresponders after PACAP-38 treatment 
A

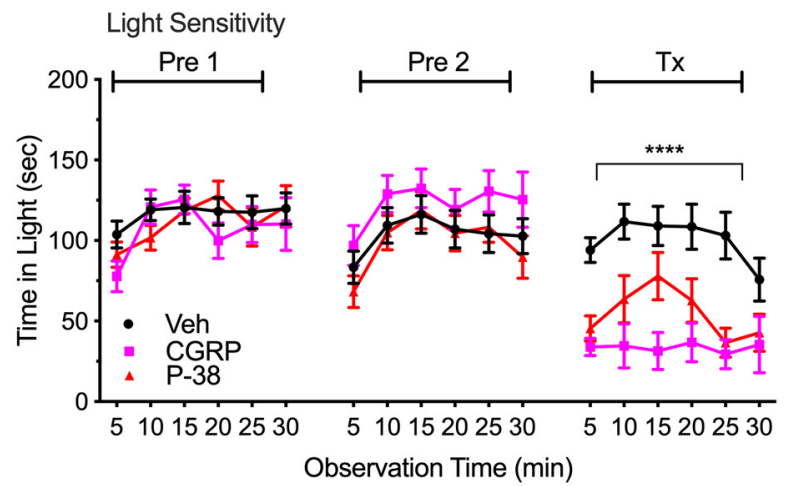

B
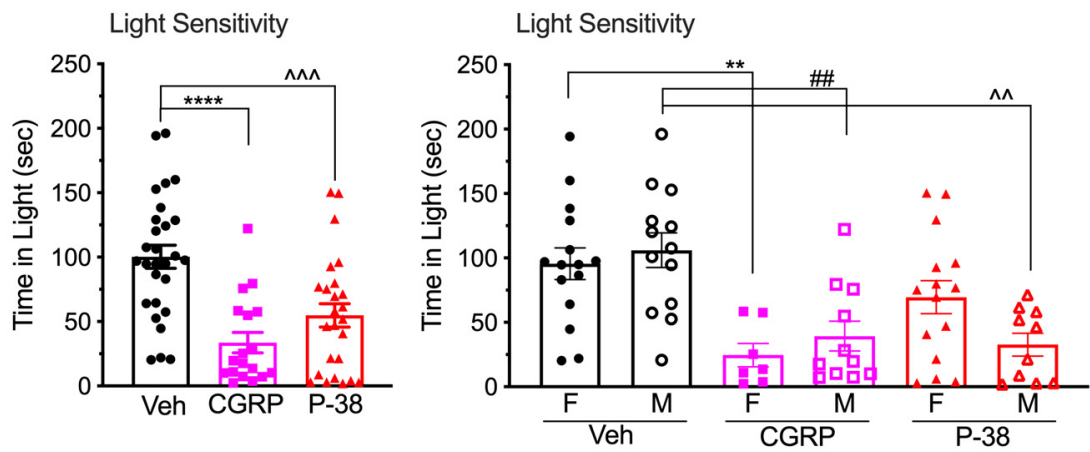

C

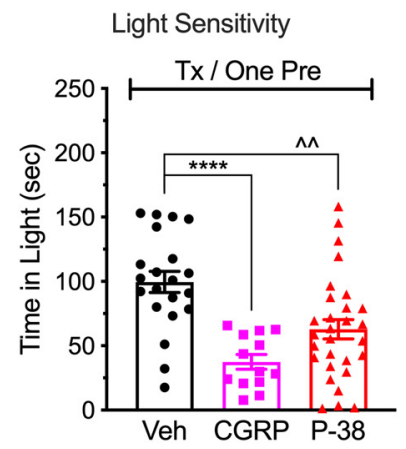

D Open Field

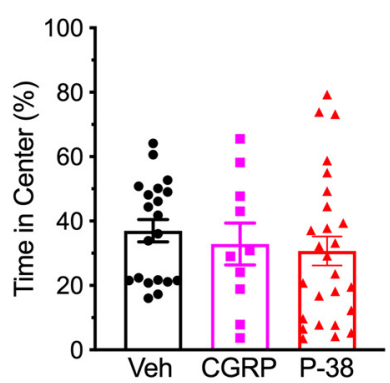

Figure 1. PACAP-38 induces light aversion in CD-1 mice. $A$, After two baseline pre-exposures in the light-dark box (Pre1, Pre2), mice were treated (Tx) with vehicle (Veh; $n=28)$, PACAP-38 (P-38; $0.3 \mathrm{mg} / \mathrm{kg}, n=25)$, or CGRP $(0.1 \mathrm{mg} / \mathrm{kg}, n=18)$. The mean ( \pm SEM) time spent in the light zone every $5 \mathrm{~min}$ over a $30 \mathrm{~min}$ period is shown for each pre-exposure and after treatment. $\boldsymbol{B}$, Left, Data from individual mice are shown with the mean ( \pm SEM) time in light per 5 min interval calculated from the entire $30 \mathrm{~min}$ testing period from $\boldsymbol{A}$. Right, Data from the left panel separated as male (M) and female (F). $C$, Effect of treatment with vehicle $(n=21)$, PACAP-38 $(0.3 \mathrm{mg} / \mathrm{kg}, n=29)$, or CGRP $(0.1 \mathrm{mg} / \mathrm{kg}, n=13)$ after only one baseline pre-exposure (Tx/0ne Pre). Data are shown for individual mice with the mean ( \pm SEM) time in light per 5 min interval from the entire 30 min testing period. D, Open field behavior of mice injected with vehicle $(n=20)$, PACAP-38 $(0.3 \mathrm{mg} / \mathrm{kg}, n=26)$, or CGRP $(0.1 \mathrm{mg} / \mathrm{kg}$, $n=10$ ). Data are shown for individual mice with the mean time (percentage $\pm S E M$ ) in the center zone. Statistics are described in Table 1. For light aversion at the later time point, see Extended Data Figure 1-1.

(Extended Data Fig. 3-3A-C). These properties were seen in both the first and second treatments. Thus, both light aversion and the associated decrease in motility were stable in the two populations.

\section{Responder and nonresponder behaviors are an inheritable trait}

To further test the differences between the two subpopulations, we bred the responder and nonresponder mice to see whether the trait was inheritable. The progeny (F1) were tested for PACAP responses in the light aversion assay twice to confirm their phenotypes. Crosses between responders and responders $(\mathrm{RxR})$ and crosses between responders and nonresponders $(\mathrm{RxN})$ yielded $88 \%$ and $73 \%$, respectively, of the progeny responding to PACAP-38 (Fig. $4 A, B$ ). In contrast, only $24 \%$ of the progeny of crosses of nonresponders with nonresponders $(\mathrm{NxN})$ responded to PACAP-38 (Fig. $4 A, B$, Extended Data Fig. 4-1). The percentage of mice that responded to PACAP38 was about the same between males and females (RxR: 90\% females; $87 \%$ males; RxN: 72\% females; $74 \%$ males). Of relevance to interpretations of this experiment, $20-33 \%$ of mice treated with vehicle had less time in the light, which would make them be considered responders by our criteria (Extended Data Fig. 4-1). We believe that this represents the inherent variability in the phenotype. In addition, PACAP reduced motility of the progeny from responder crosses (both $\mathrm{RxR}$ and $\mathrm{RxN}$ ), but not in the nonresponder $\mathrm{NxN}$ crosses (Extended Data Fig. 4-2). This was seen as both increased resting in the dark zone and decreased transitions between the light and dark zones (rearing behavior could not be measured because of a technical error). These results establish that the responder and nonresponder phenotypes are hereditary based on the high association between mating pair type and responder status (Pearson $\chi^{2}$ test, $p=1.48 \mathrm{e}-09$ ).

The high prevalence of responders when at least one of the parental mice was a responder (both $\mathrm{RxR}$ and $\mathrm{RxN}$ crosses) suggested a dominant inheritance pattern. However, a likelihood ratio test revealed that there was a difference between the crosses $(p=0.0306)$, which meant that inheritance of a segregating allele with a dominant effect was not statistically supported by the data. Thus, the crosses indicate that responder status is hereditary, but apparently not by a simple dominance mechanism.

\section{Differences in gene expression and genotypes between responder and nonresponder mice}

To evaluate potential gene expression differences between responder and nonresponder mice, we focused on trigeminal ganglia. While the best tissue to analyze is not known, we reasoned that trigeminal ganglia are a good starting point since they are activated during photophobia and migraine (Moulton et al., 2009; Noseda and Burstein, 2013). RNA sequences were analyzed from six PACAP-38 responder and six nonresponder mice, with an equal number of both sexes. The mice were the F1 progeny from two independent crosses of responder mice and two independent crosses of nonresponder mice. Phenotypes of both parental and F1 progeny were confirmed by two sequential PACAP-38 treatments $(0.3 \mathrm{mg} / \mathrm{kg}), 2 \mathrm{~d}$ apart, with testing at $30 \mathrm{~min}$ postinjection. Hierarchical clustering of the RNA-seq data in a heat map 
A

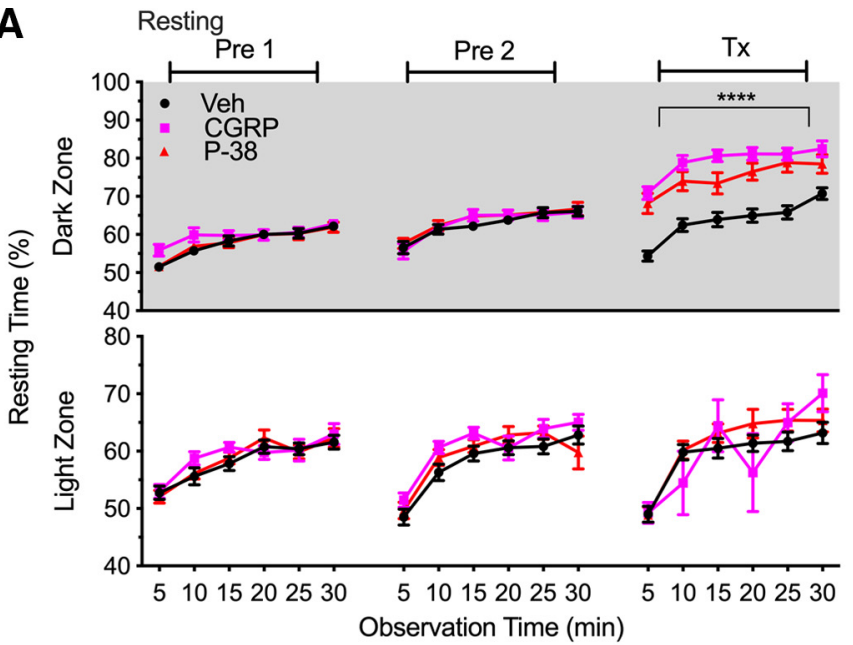

B

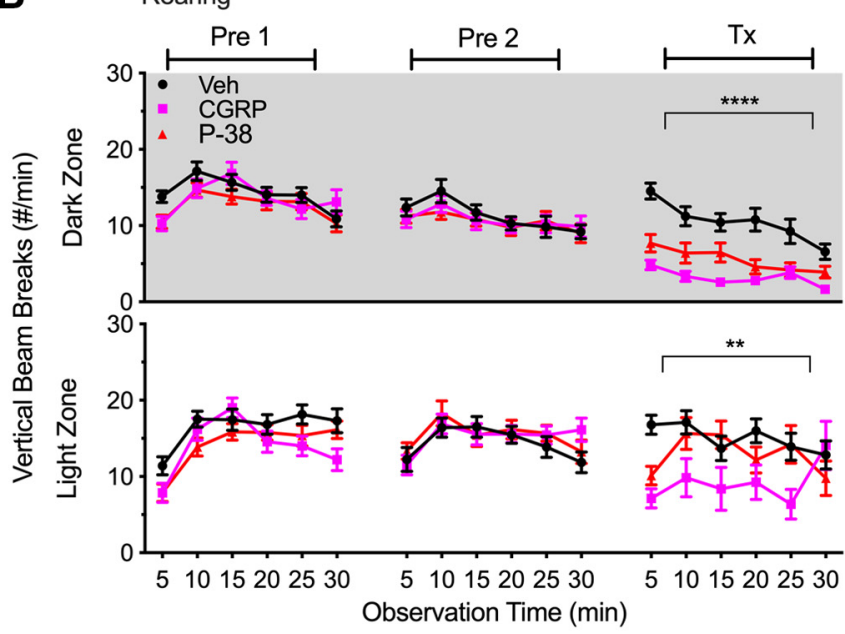

C

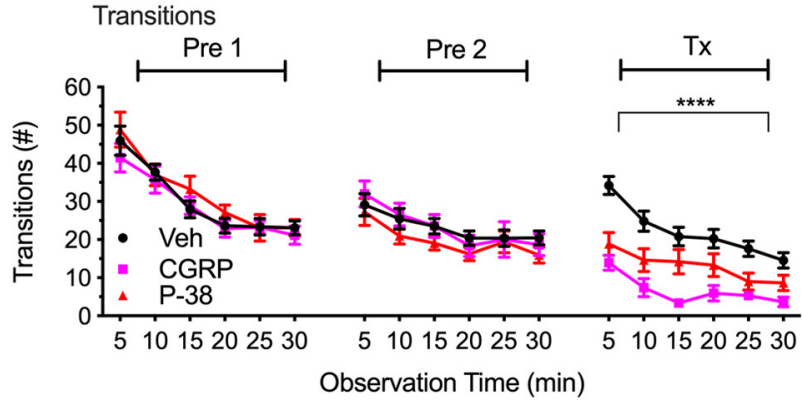

Resting

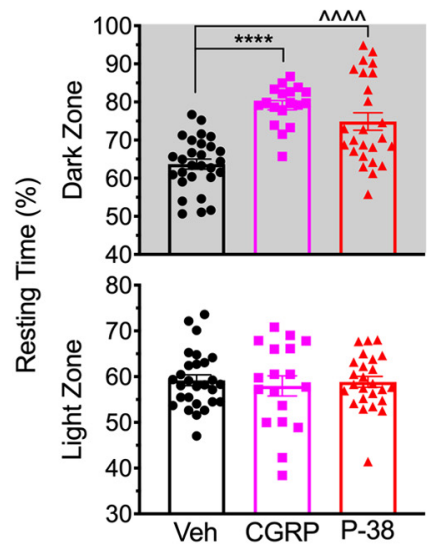

Rearing

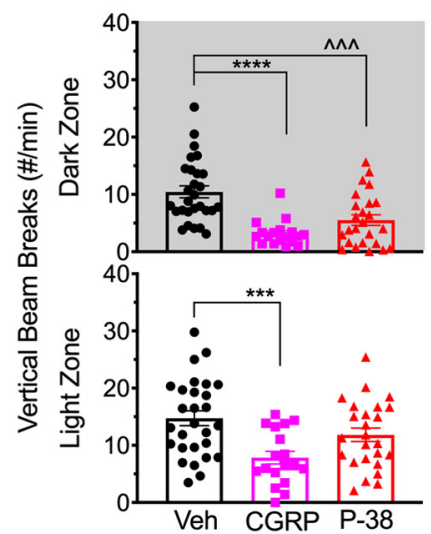

Transitions

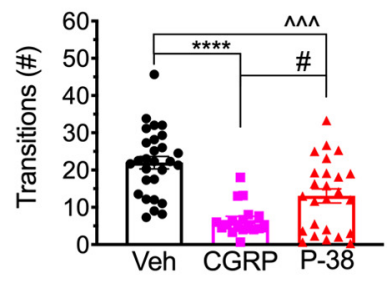

Figure 2. PACAP-38 reduces motility. Motility data were collected at the same time as light aversion data from the same mice shown in Figure 1, $A$ and $B$. After two baseline pre-exposures (Pre1, Pre2), mice were treated (Tx) with vehicle (Veh; $n=28)$, PACAP-38 (P-38; $0.3 \mathrm{mg} / \mathrm{kg}, n=25)$, or CGRP $(0.1 \mathrm{mg} / \mathrm{kg}, n=18)$. $A$, Resting time in light and dark zones. Left, Percentage ( \pm SEM) of time spent resting in each zone every 5 min over the 30 min testing period. Right, Data for individual mice from treatment day shown as the mean percentage of time ( \pm SEM) spent resting in each zone per $5 \mathrm{~min}$ interval. $\boldsymbol{B}$, Rearing in light and dark zones.Left, Mean ( \pm SEM) number of vertical beam breaks in each zone every 5 min over the 30 min testing period. Right, Data for individual mice from treatment day shown as the mean ( \pm SEM) number of vertical beam breaks in each zone per 5 min interval. $C$, Transitions between the light and dark zones. Left, Mean ( \pm SEM) number of transitions every 5 min over the 30 min testing period. Right, Data for individual mice from treatment day shown as the mean ( \pm SEM) number of transitions per $5 \mathrm{~min}$ interval. Statistics are described in Table 1. For correlation between time in light and motility, see Extended Data Figure 2-1.

revealed that PACAP responders and nonresponders formed two distinct groups (Fig. 5A). Thus, the groups could be distinguished not only by phenotype, but also based on differential gene expression in trigeminal ganglia.

A total of 148 genes had significantly different expression between the two cohorts (Extended Data Fig. 5-1). Genes more highly expressed in responders are designated with a positive $\log 2$ fold change (FC) value, while those expressed at a lower level in responders have a negative log2 FC value. While both male and female mice were responders and nonresponders, because there was a trend for greater responses in male mice, the RNA data were analyzed with sexes together and separately (Extended Data Figs. 5-2, 5-3). When both sexes were analyzed together, of the 148 differentially expressed genes, 50 were more highly expressed in responder mice. One striking finding was that responder mice have greater expression (4-6 log2 FC) of pituitary hormone and receptor RNAs. Specifically, the gonadotropin-releasing hormone receptor (Gnrhr; Fig. 5B) and the 

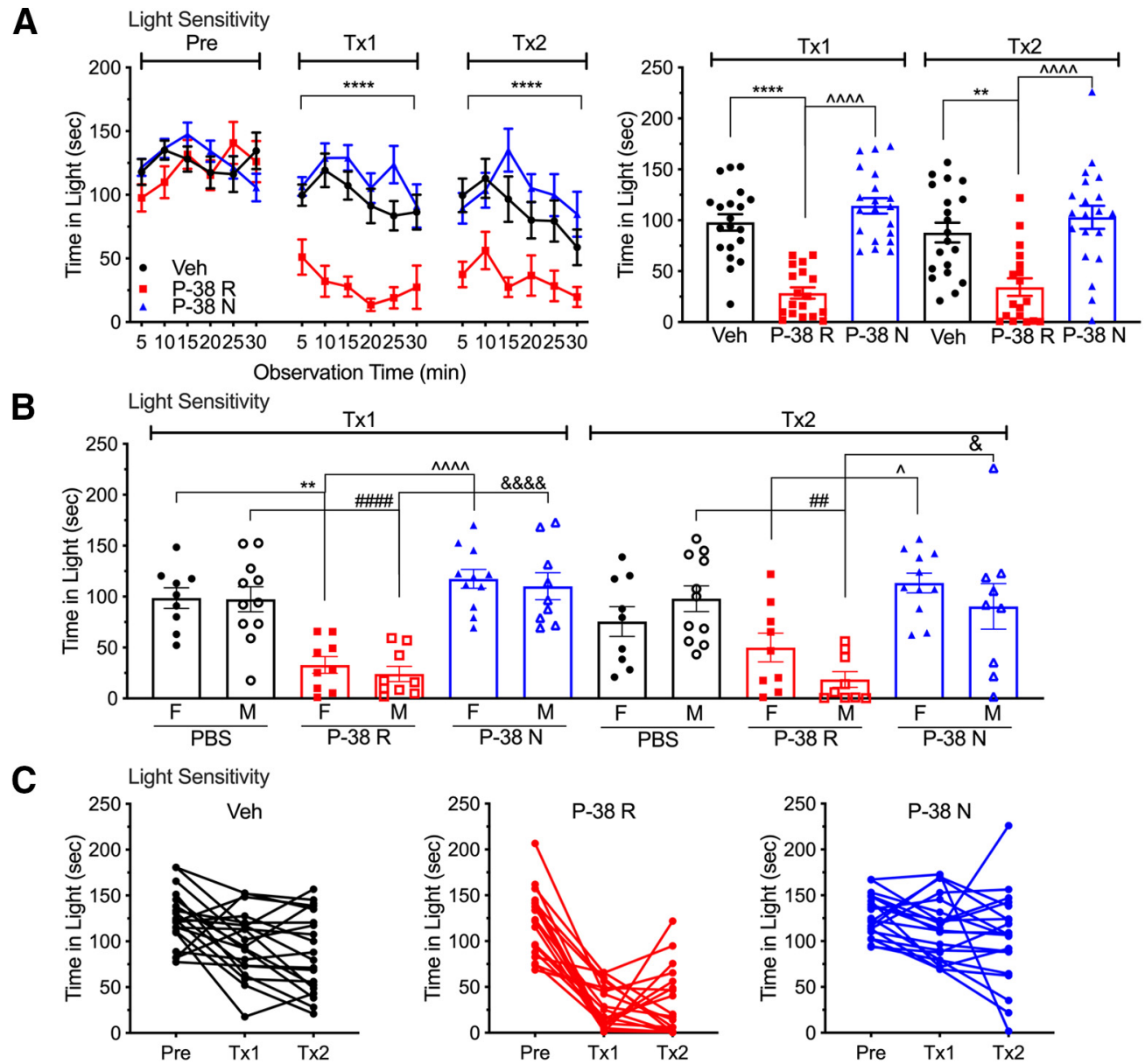
A
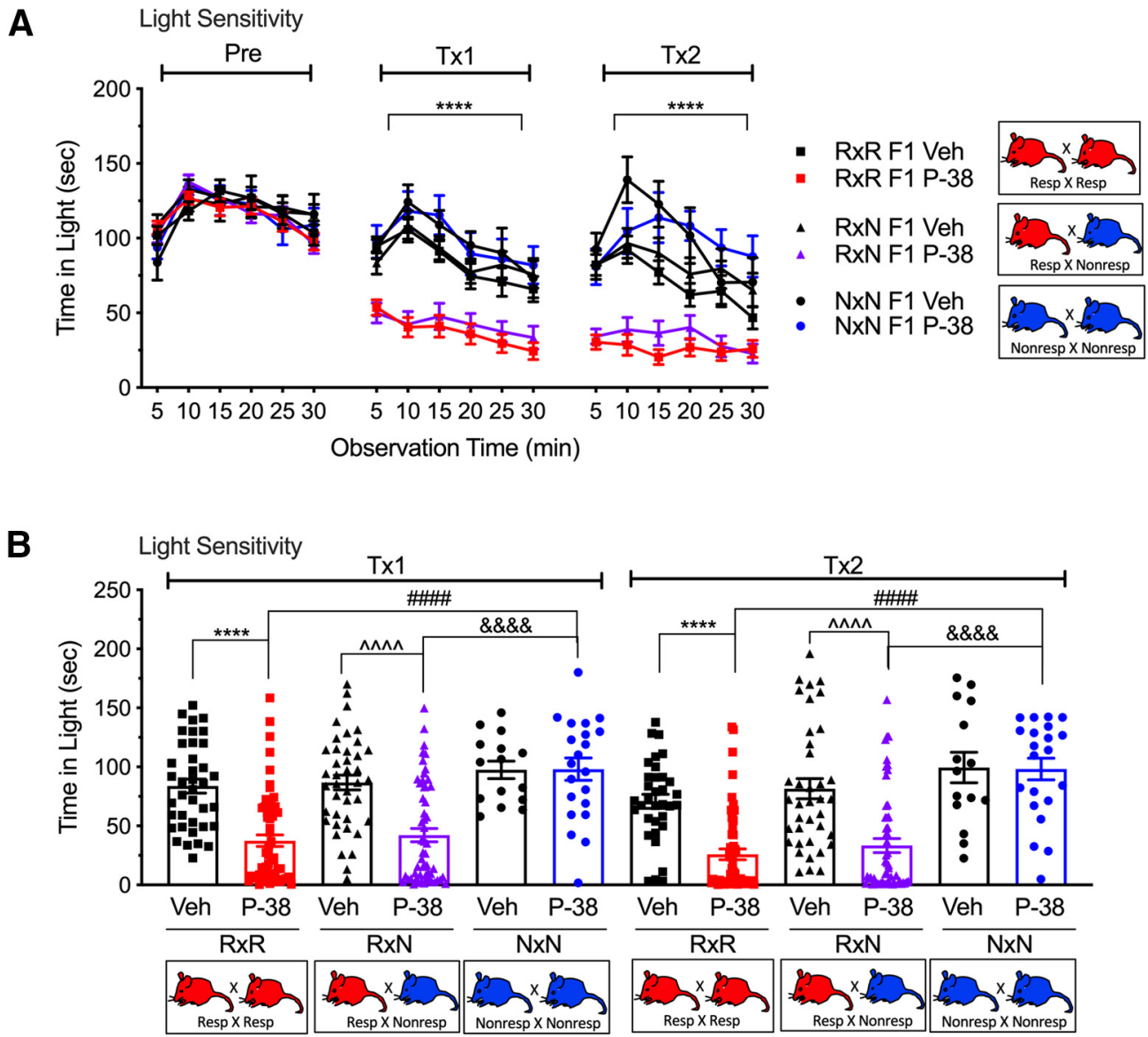

Figure 4. Light aversion in $\mathrm{F} 1$ responders and nonresponders. $A$, F1 progeny of crosses between responder and responder mice (RxR), responder and nonresponder mice (RxN), and nonresponder and nonresponder mice $(\mathrm{NxN})$ were given one pre-exposure to the testing chamber (Pre), then treated (Tx1) with vehicle (Veh; RxR, $n=38 ; \mathrm{RxN}, n=40$; NxN, $n=15$ ), or PACAP-38 (P-38; $0.3 \mathrm{mg} / \mathrm{kg} ; \mathrm{RxR}, n=59 ; \mathrm{RxN}, n=56 ; \mathrm{NxN} n=21$ ). After $3 \mathrm{~d}$, the same mice were treated and tested again (Tx2). The mean ( \pm SEM) time spent in the light zone every 5 min over a 30 min period is shown for each test day. $\boldsymbol{B}$, Data from individual mice are shown with the mean ( \pm SEM) time in light per 5 min interval over the entire 30 min testing period from $\boldsymbol{A}$. Statistics are described in Table 1. For the percentage of progeny responders, see Extended Data Figure 4-1. For motility, see Extended Data Figure 4-2.

G-protein-coupled receptors and peptide hormones (Extended Data Fig. 5-5). The pathways involving hormone ligand-binding receptors and glycoprotein hormones were exemplified by the expression of Cga, Tshb, Gnrhr, Lhb, and Fshb. These highly expressed genes were also overrepresented in a number of pathways involved in pain modulation. These include the neuroactive ligand-receptor interaction [false discovery rate (FDR) $<0.001$; Jeong et al., 2018; Deng et al., 2018a], and signaling by G-protein-coupled receptors (FDR $<0.001$; Stone and Molliver, 2009; Cottrell, 2019) and the prolactin signaling pathway (FDR $<0.05$; Avona et al., 2019).

Similarly, a gene ontology analysis that shows connections between genes and their biological and cellular functions also revealed over-representation of genes in biological processes related to hormone signaling, including peptide hormone processing (FDR $<0.001)$, G-protein-coupled receptor signaling pathway (FDR $<0.01$ ), and regulation of signaling receptor activity $(\mathrm{FDR}<0.01$; Extended Data Fig. 5-6). These genes included Cga, Tshb, Lhb, Fshb, and Nts. Analysis of the gene ontology by sex also revealed peptide hormone processing, hormone activity, and pituitary gonadotropin complex in the male responder cohort, but not the female responder cohort.

In contrast to genes more highly expressed in responder mice, the lower expressed genes were less informative. There were 98 genes with lower expression in responder mice (Extended Data Fig. 5-1). In general, these genes were overrepresented in pathways such as platelet activation, signaling, and aggregation (FDR $<0.05)$, which is consistent with other studies showing PACAP being an inhibitor of platelet activation (Freson et al., 2004; Eneman et al., 2015; Extended Data Fig. 5-7). Other pathways include PI3K-Akt signaling pathway $($ FDR $<0.05)$ and arachidonic acid metabolism (FDR $<0.05)$, which have been suggested to be involved in migraine (PuigParellada et al., 1993; Liu et al., 2017). Gene ontology revealed a number of biological functions involved in bone mineralization and ossification (Extended Data Fig. 5-8). Genes involved in these biological functions include $B M P-7$, which is known to be negatively regulated by PACAP (Drahushuk et al., 2002).

In addition to gene expression, we also investigated sequence differences between responder and nonresponder mice. Genetic variance was expected since the CD-1 strain is outbred and the responders and nonresponders came from two litters each. Using FaST-LMM, which estimates and accounts for genetic relatedness, we identified 162 SNP sites that had distinctly different genotypes between responder and nonresponder mice but were the same for all six mice (male and female) in each of the two groups. None of the other SNPs reached genome-wide significance (Extended Data Fig. 5-9). The 162 SNPs were classified as 17 missense variations, 61 synonymous variations, $145^{\prime}$ untranslated region (UTR) variations, $663^{\prime}$ UTR variations, 3 upstream gene variations, and 1 intron variation based on SNPEff analysis (Cingolani et al., 2012; Extended Data Fig. 5-10). Among the SNPs, three were in genes identified as 
A

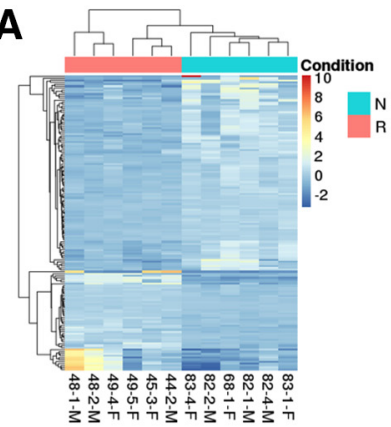

D

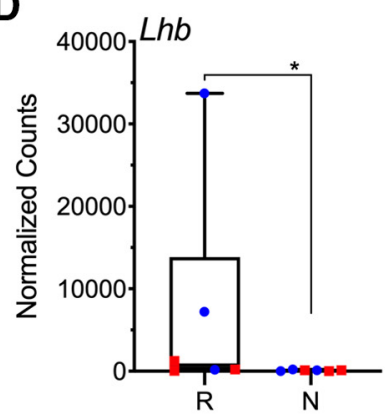

G

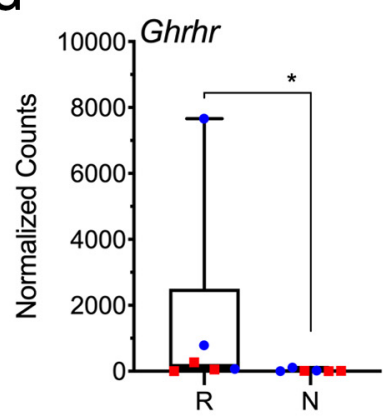

J

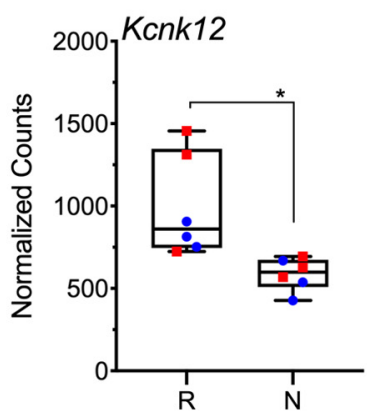

B

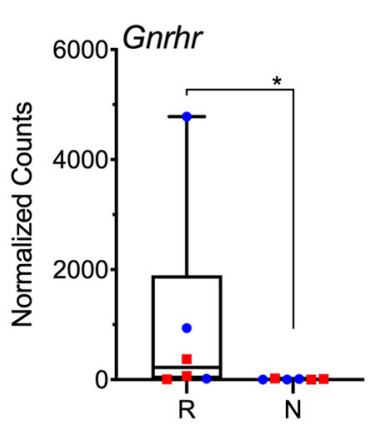

E

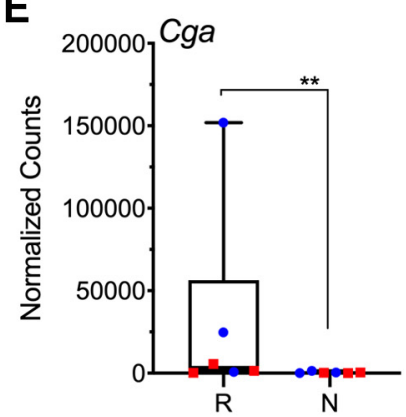

H

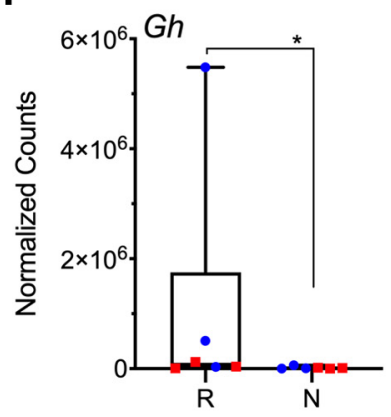

K

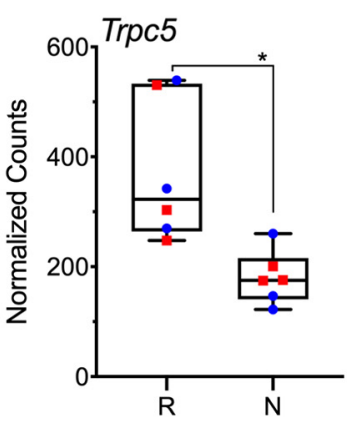

C

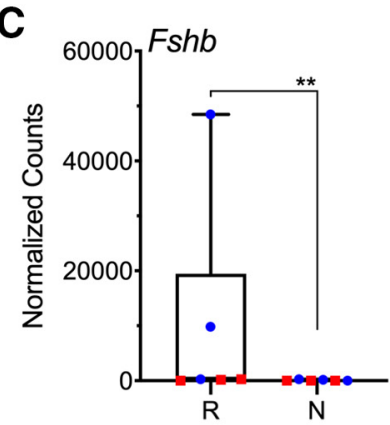

F

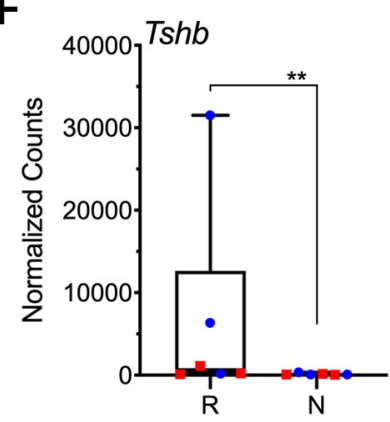

I

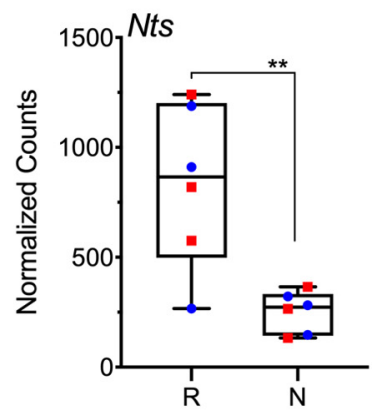

L

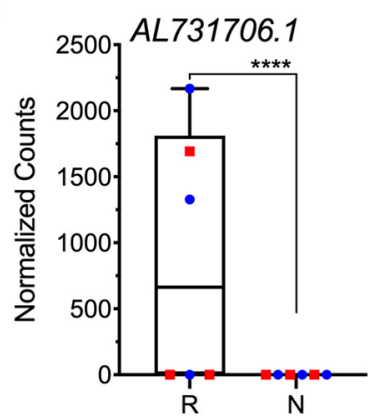

Figure 5. Differential gene expression between responder and nonresponder mice. Gene level counts were normalized to size factors calculated by DESeq2 to correct for library size. Normalized counts were compared between responders and nonresponders using the Wald test for significance. Male and female mice in each cohort are indicated by blue and red symbols, respectively. $\boldsymbol{A}$, Heat map reflects gene expression differences between responder ( $\mathrm{R}$; orange) and nonresponder ( $\mathrm{N}$; teal) mice on the $x$-axis from the list of differentially expressed genes in Extended Data Figure 5-1 that are grouped on the $y$-axis. Mouse number and sex [male (M) and female (F)] are indicated. Mouse numbers with the same first numbers (e.g., 48) indicate mice

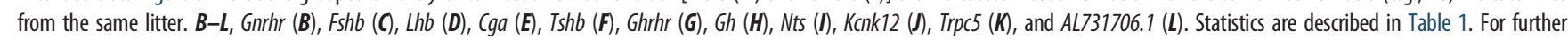
details, see Extended Data Figures 5-1, 5-2, 5-3, 5-4, 5-5, 5-6, 5-7, 5-8, 5-9, and 5-10. For qPCR results, see Extended Data Figure 5-11.

differentially expressed between responder and nonresponder mice: in the coding region of Atg10 and the untranslated region of Kcnk12 and Pmp2. None of the variants were in PACAP receptor genes. Pathway analysis did not reveal any pathways that were significantly overrepresented with genes impacted by missense variation. Similarly, no biological, cellular, or molecular processes was overrepresented by these genes.

To replicate and validate the RNA-seq data, we then tested a completely different cohort of mice by qPCR. This additional test was designed to overcome the limitation of natural variation in gene expression in an outbred strain that was inherent in the small discovery cohort from the RNA-seq study. Hence, any genes that were replicated must be fairly robust and at the same time the lack of replication does not necessarily negate the initial RNA-seq finding.

The new set of mice were tested with two sequential PACAP treatments to identify responders and nonresponders. However, unlike the RNA-seq cohorts, we did not use F1 progeny. RNA 
from male and female responders $(n=12)$ and nonresponders $(n=12)$ was isolated from trigeminal ganglia. Among the 11 genes selected for qPCR analysis, there was considerable variability among the mice in each cohort (Extended Data Fig. 5-11). This was expected from the variability of the RNA-seq data. Only one gene, $\operatorname{Trpc5}$, reached statistical significance between responders and nonresponders, and only for male mice. However, while not statistically significant, the gonadotropin receptor (Gnrhr) and glycoprotein hormone genes ( $L h b, T s h b$, $C g a$ ) had higher median values in male mice that were at or above the first quartile of the nonresponder mice. This trend is consistent with the RNA-seq data indicating higher expression in males. The ion channel Kcnk12 also had a trend toward higher expression in the male mice. While the qPCR data for Nts, Drd2, Prl, Rest, and Trpm8 did not have an apparent difference between either male or female responder and nonresponder cohorts, there were individual mice that matched the RNA-seq results. As a control, the housekeeping genes had very little variability across cohorts. Ct values for Hprt averaged 16.62 \pm 0.055 ( \pm SEM), and Ppia averaged $12.98 \pm 0.031$.

\section{Pretreatment with anti-PACAP monoclonal antibodies attenuates light aversion induced by both PACAP-38 and PACAP-27}

We tested whether anti-PACAP monoclonal antibodies would be able to attenuate PACAP-induced light aversion using the same sequential treatment paradigm previously used with CGRP antibodies (Mason et al., 2017). For all antibody experiments, mice were prescreened for their response to PACAP, and only the responder mice were further analyzed. After the first PACAP injection [treatment 1 (Tx1): pre-Ab], mice that responded to PACAP-38 spent significantly less time in the light compared with vehicle-treated mice (Fig. 6A,B). The mice that responded to PACAP-38 in the first treatment were then given either control isotype or anti-PACAP antibody. One day after antibody injection, mice were injected with PACAP-38 and tested for light aversion (Tx2: post-Ab). Pretreatment with anti-PACAP antibody fully attenuated the effect of PACAP-38 (Fig. 6A,B). Mice treated with anti-PACAP antibody before PACAP-38 were indistinguishable from those treated with vehicle with either control or PACAP antibody, while those treated with the control antibody before PACAP-38 spent significantly less time in the light compared with mice treated with anti-PACAP antibody or vehicle plus control or anti-PACAP antibody (Fig. 6B). Along with light aversion, antibody pretreatment also blocked the effect the PACAP-38 had on resting, rearing behavior, and transitions (Extended Data Fig. 6-1).

Since in vitro tests had shown that the PACAP antibody binds both PACAP-38 and PACAP-27 (Moldovan Loomis et al., 2019), we asked whether the antibody could also block PACAP27 actions. This question was relevant because PACAP-38 and PACAP-27 have the same receptor binding affinities and both can induce migraine in patients (Nilsson et al., 1994; Schytz et al., 2009; Hirabayashi et al., 2018; Ghanizada et al., 2020). The first step was to test the ability of PACAP-27 to induce light aversion in CD-1 mice. The mice were first treated with PACAP-38 (Tx1: P-38) as a control to confirm the response rate, before treatment with PACAP-27 (Tx2: P-27; $0.2 \mathrm{mg} / \mathrm{kg}$, equimolar to $0.3 \mathrm{mg} / \mathrm{kg}$ PACAP-38). When tested at $30 \mathrm{~min}$ after injection, the mice responded to PACAP-38, but not to PACAP-27 (Fig. 7A). There was also no effect of PACAP-27 on motility under this condition (Extended Data Fig. 7-1). Given that the two PACAP isoforms may have different stabilities (Bourgault et al., 2008), we tested them immediately after injection. Under these conditions, both PACAP-27 and PACAP-38 caused significant light aversion compared with vehicle, but PACAP-27 was significant only in the first $15 \mathrm{~min}$ postinjection (Fig. $7 B$ ). As with PACAP38 , there was a corresponding decrease in motility during this period (Extended Data Fig. 7-1). Likewise, there was a trend toward the male mice spending less time in the dark, but it was not significant.

Hence, following antibody pretreatments, we tested mice immediately after PACAP-27 injection. As with the PACAP-38 paradigm, we first treated the mice with PACAP-27 to identify the responder population (Fig. $7 C, D$ ). Subsequent pretreatment with anti-PACAP antibody blocked the effect of PACAP-27 (Fig. 7C, $D)$. As a control, mice treated with PACAP-27 and control antibody spent significantly less time in light compared with mice treated with PACAP-27 plus anti-PACAP antibody or vehicle plus control antibody (Fig. $7 C, D$ ). Antibody pretreatment also blocked the effect of PACAP-27 on resting, rearing, and transitions (Extended Data Fig. 7-2).

\section{Anti-PACAP antibodies do not inhibit CGRP-induced light aversion, nor do anti-CGRP antibodies inhibit PACAP- induced light aversion}

PACAP and CGRP have similar biological activities (Kaiser and Russo, 2013), and PACAP has been reported to elicit CGRP release (Jansen-Olesen et al., 2014), which raises the question whether the two peptides might act in series to trigger migraine. To address this relationship, anti-PACAP and anti-CGRP antibodies were tested for their ability to cross-inhibit light aversion induced by PACAP or CGRP. We first tested whether antiPACAP antibody could inhibit CGRP-induced light aversion. Mice were treated with CGRP, which caused significant light aversion compared with vehicle-treated mice (Fig. 8A,B). The day before the second CGRP treatment, mice were given either control antibody or anti-PACAP antibody. Treatment of mice with anti-PACAP antibody did not ameliorate light aversion to CGRP compared with vehicle or control antibody groups (Fig. $8 A, B)$ and were not significantly different from each other. Thus, pretreatment with anti-PACAP antibody was not able to inhibit the effect of CGRP. Consistent with the light aversion, the PACAP antibody was not able to inhibit CGRP effects on motility (Extended Data Fig. 8-1).

Finally, we tested whether an anti-CGRP antibody could inhibit PACAP-induced light aversion. Mice were first treated with PACAP-38 and both cohorts of responders spent significantly less time in the light compared with the vehicle groups (Fig. 9A,B). The mice that responded to PACAP-38 in the first treatment were then given either the control isotype or anti-CGRP antibody. One day after antibody injection, mice were injected with PACAP-38 again and assessed for light aversion. Pretreatment with anti-CGRP antibody was not able to inhibit the effect of PACAP-38 (Fig. 9A,B). Anti-CGRP antibody was also not able to rescue the effect PACAP had on motility (Extended Data Fig. 9-1).

\section{Discussion}

In this study, we report that PACAP can induce light aversion in mice. This is consistent with the ability of PACAP to induce migraine and photophobia in people (Schytz et al., 2009) and with a previous report that PACAP-38 elicited light aversion in mice on a CD-1 background (Markovics et al., 2012). While they did not report populations of responders and nonresponders, this may be explained by different sources of mice and/or genetic 
A

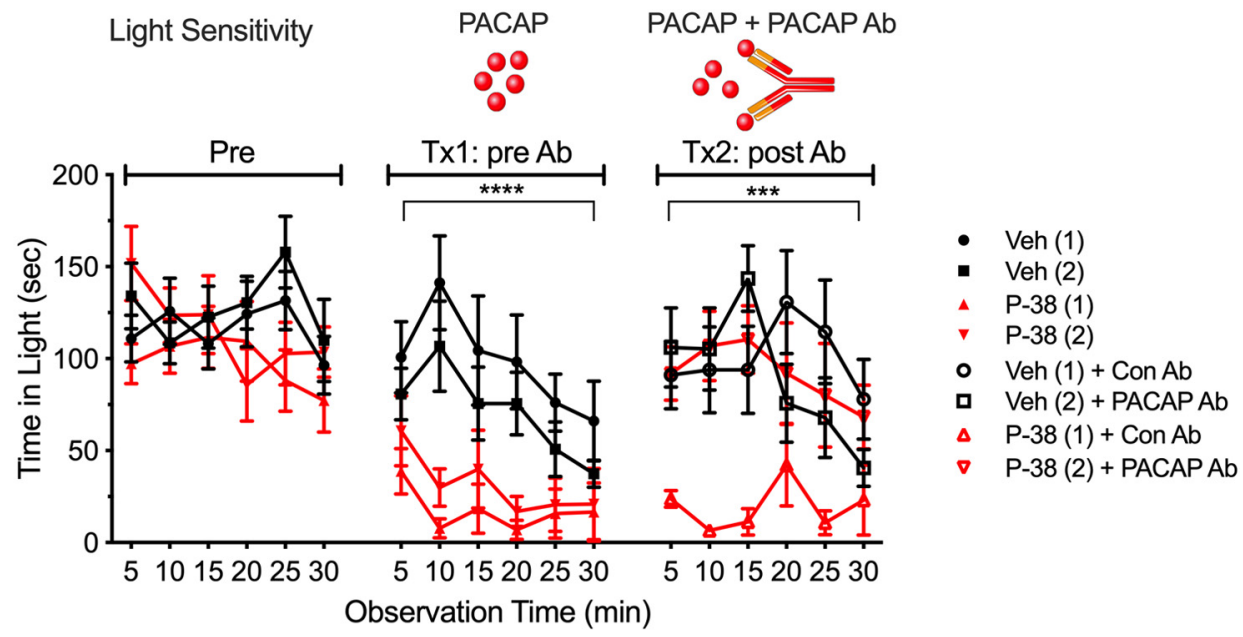

B

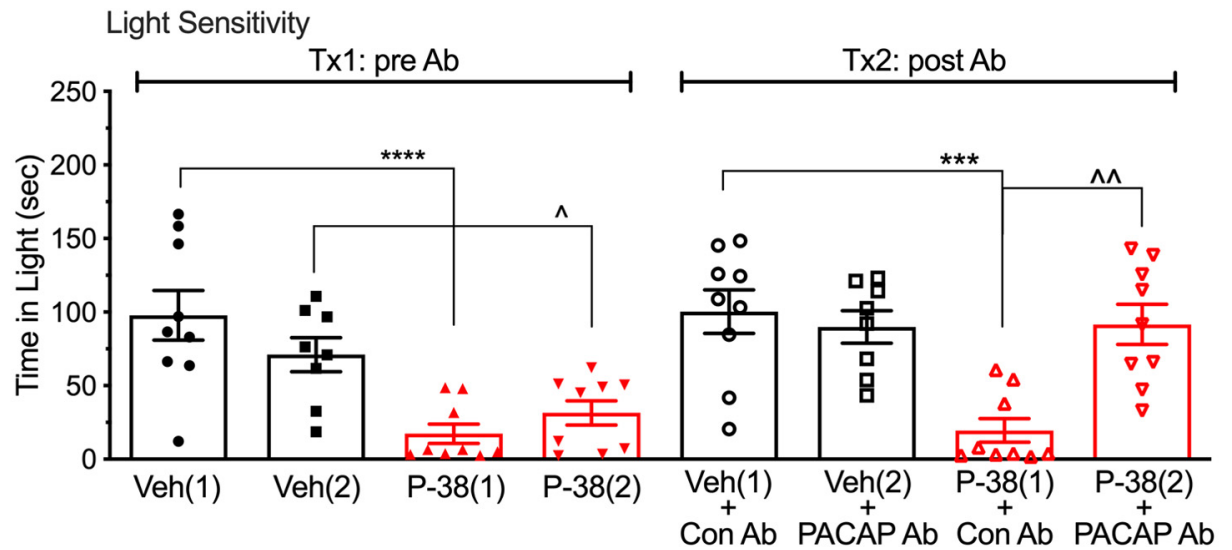

Figure 6. Pretreatment with anti-PACAP antibody inhibits PACAP-38-induced light aversion. $\boldsymbol{A}$, Male and female mice were divided into four groups, two of which would eventually get vehicle and two that would get PACAP-38. After a baseline pre-exposure (Pre), but before antibody treatments, mice were treated (Tx1: pre Ab) with vehicle [Veh(1), $n=9$; Veh(2), $n=9]$ or PACAP-38 [0.3 mg/kg; P-38(1), $n=9 ;$ P-38(2), $n=9]$. Three days after Tx1 mice were given an injection of control antibody (Con Ab) or anti-PACAP antibody (PACAP Ab), then $24 \mathrm{~h}$ later, mice were treated with vehicle or PACAP again (Tx2: $24 \mathrm{~h}$ post Ab). Mean ( \pm SEM) time spent in the light compartment every 5 min over a 30 min period is shown. $\boldsymbol{B}$, Data for individual mice from each treatment day are shown as the mean time ( \pm SEM) in light per 5 min interval. Statistics are described in Table 1. For motility, see Extended Data Figure 6-1.

homogeneity in their transgenic CD-1 line. Compared with CGRP, the PACAP-evoked light aversion and reduced motility in mice is similar to the effects of CGRP in this and a previous study (Mason et al., 2017). In particular, the mice rested more, but only in the dark zone, which is reminiscent of migraine patients preferring to rest in the dark.

A strength of this study was that we used CD-1 mice, which are a genetically diverse, outbred strain of mice. This strategy revealed distinct groups of PACAP responders and nonresponders that may be predictive of variability expected in humans (Aldinger et al., 2009). The responder and nonresponder phenotypes were stable and inheritable. While the inheritance pattern appeared to be dominant, this was not supported statistically, which suggests multigenic inheritance or incomplete penetrance. To understand the genetic basis underlying the responder phenotype, we performed an RNA-seq analysis of trigeminal ganglia, which revealed a number of candidate genes, including pituitary hormones, receptors, and ion channels.

Perhaps most intriguing among the candidate genes is the elevation of pituitary glycoprotein hormones and receptor RNAs in the trigeminal ganglia of male responder mice. RNAs for the gonadotropin hormones FSH and $\mathrm{LH}$, along with the receptor that controls their release (GnRHR) were elevated in a subset of males. Gonadotropin-releasing hormone is expressed in trigeminal ganglia neurons believed to be involved in nociception and chemosensory avoidance (Umatani and Oka, 2019). Increased expression of GnRHR in responder mice could thus enhance a local positive feedback loop. How these hormones, as well as other changes in hormone and receptor RNA levels observed between the responder and nonresponder populations, may facilitate PACAP actions remains to be seen.

A second interesting set of genes are the Trpc5 and Kcnk12 ion channel RNAs, which were elevated in both male and female PACAP responder mice. Trpc5 can directly detect mechanical stimulation as membrane stretch (Shen et al., 2015) and can mediate persistent tactile pain in rodent models of inflammation (Sadler et al., 2021). This raises the possibility that Trpc5 might contribute to peripheral sensitization by sensing vascular tone in the dura or cutaneous stimuli. Increased expression of the potassium channel Kcnk12 in PACAP responder mice is intriguing given that a related family member, KCNK18 (TRESK), has been linked to migraine with aura (Lafrenière et al., 2010). While Kcnk12 is known to be expressed in the trigeminal ganglia (Manteniotis et al., 2013), little is known about its function (Marsh et al., 2012; Bichet et al., 2015). Other RNAs were elevated in the responder and nonresponder populations in both sexes or in only males or females. While their roles are not established, four of the genes (Rest, Kcnk5, Trpm8, Mlf1) are among 

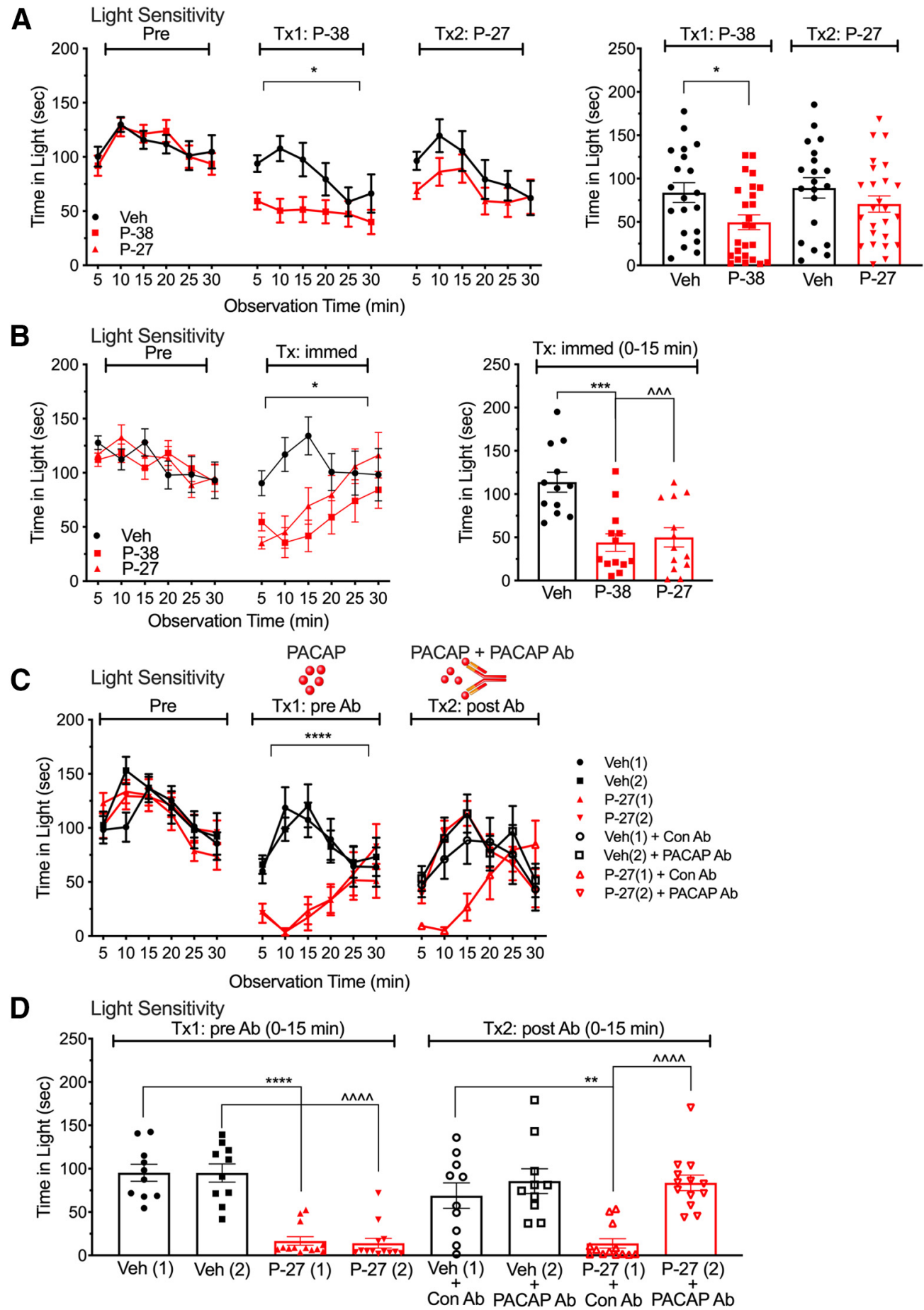

Figure 7. Immediate injection of PACAP-27 induces light aversion that can be blocked by anti-PACAP antibody. $A$, After a baseline pre-exposure (Pre), male and female mice were treated (Tx1: P-38) with vehicle (Veh; $n=20)$ or PACAP-38 (P-38; $0.3 \mathrm{mg} / \mathrm{kg}, n=25)$ and assessed for light aversion 30 min postinjection. Three days later, the same mice were treated (Tx2: P-27) with vehicle or PACAP-27 (P-27; $0.2 \mathrm{mg} / \mathrm{kg}$ ) and assessed for light aversion $30 \mathrm{~min}$ postinjection. Left, Mean ( \pm SEM) time spent in the light every 5 min over a 30 min period is shown for each test day. Right, Data for individual mice from treatment days shown as the mean ( \pm SEM) in light per 5 min interval. $\boldsymbol{B}$, After Pre, mice were treated and tested immediately (Tx: immed) after injection of vehicle $(n=12), P-38(0.3 \mathrm{mg} / \mathrm{kg}, n=14)$, or P-27 $(0.2 \mathrm{mg} / \mathrm{kg}, n=13)$. Left, Mean ( \pm SEM) time spent in the light compartment every 5 min over the $30 \mathrm{~min}$ test period. Right, Data for individual mice from the first 15 min of treatment shown as the mean ( \pm SEM) in light per 5 min interval. C, Male and female mice were divided into four groups, two of which would eventually get vehicle and two that would get PACAP-27. After a baseline Pre, but before antibody treatments, mice were treated (Tx1: pre Ab) with vehicle [Veh(1), $n=10$; Veh(2), $n=10]$ or PACAP-27 [0.2 mg/kg; P-27(1), $n=13 ; \mathrm{P}-27(2), n=13]$. Three days after Tx1 mice were given an injection of control antibody (Con Ab) or anti-PACAP antibody (PACAP Ab), then $24 \mathrm{~h}$ later, mice were treated with vehicle or PACAP again (Tx2: post Ab). Mean ( \pm SEM) time spent in the light compartment every 5 min over a 30 min period is shown. D, Data for individual mice from the first 15 min of treatment before antibody [Tx1: pre Ab (0-15 min)] and after antibody [Tx2: post Ab (0-15 min)] shown as the mean \pm SEM in light per 5 min interval. Statistics are described in Table 1. For motility, see Extended Data Figures 7-1 and 7-2. 


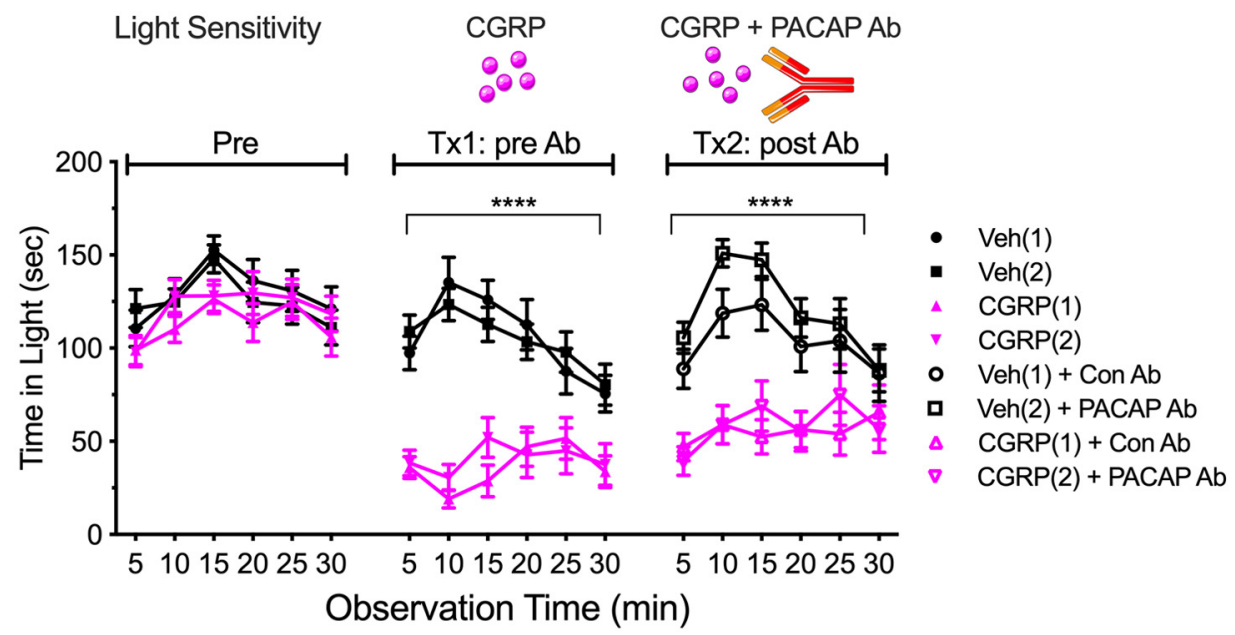

B

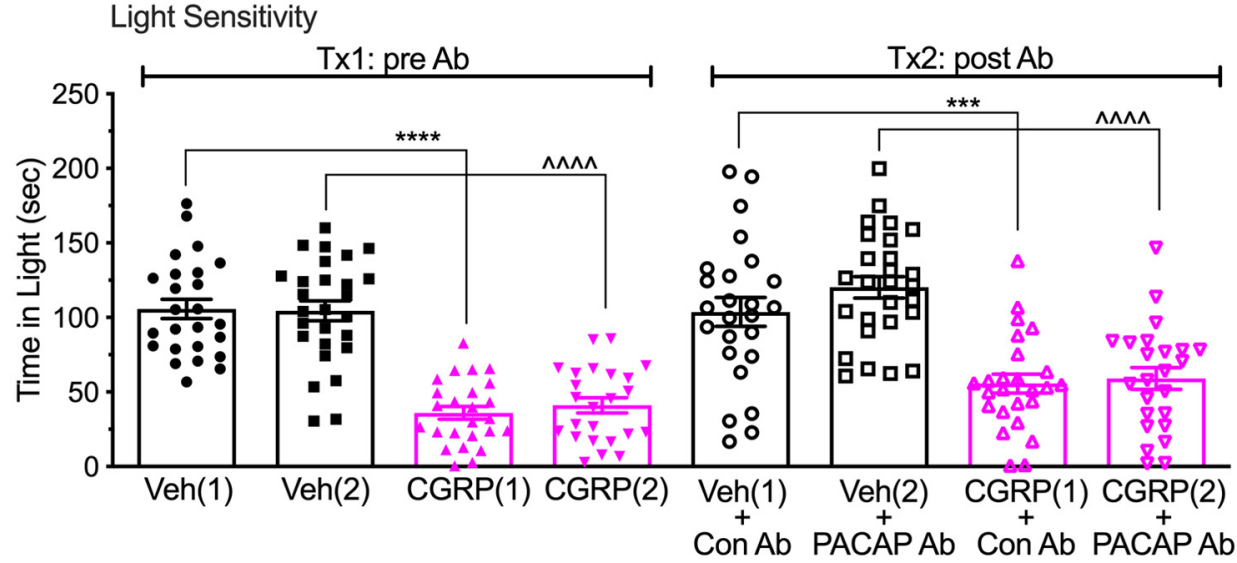

Figure 8. Anti-PACAP antibody does not inhibit CGRP-induced light aversion. $\boldsymbol{A}$, Male and female mice were divided into four groups, two of which would eventually get vehicle and two that would get CGRP. After a baseline pre-exposure (Pre), but before antibody treatments, mice were treated (Tx1: pre Ab) with vehicle [Veh(1), $n=25 ;$ Veh(2), $n=28]$ or CGRP [0.1 mg/kg; $\operatorname{CGRP}(1), n=25$; $\operatorname{CGRP}(2), n=24]$. Three days after Tx1, mice were given an injection of control antibody (Con Ab) or anti-PACAP antibody (PACAP Ab), then $24 \mathrm{~h}$ later, mice were treated with vehicle or (GRP again (Tx2: post Ab). The mean ( \pm SEM) time spent in the light compartment every 5 min over a 30 min period is shown. $\boldsymbol{B}$, Data for individual mice from each treatment day are shown as the mean time ( $($ SEM) in light per $5 \mathrm{~min}$ interval. Statistics are described in Table 1. For motility, see Extended Data Figure 8-1.

the 38 loci associated with migraine in a large genome-wide association study (Gormley et al., 2016). Finally, SNPs were identified in the Kcnk12 and Pmp2 (myelin protein 2) untranslated regions and coding region of Atg10 (E2-like enzyme involved in autophagy). Future studies understanding the roles of these SNPs and the differentially expressed genes may prove to be important in trigeminal pain states.

Given the variability seen within the RNA-seq cohorts, we generated a second independent group of PACAP responders and nonresponders for $\mathrm{qPCR}$ gene expression analysis. Because we were using independent cohorts of outbred mice, it is important to emphasize that the lack of replication does not necessarily negate the RNA-seq finding. As with RNA-seq, there was considerable heterogeneity within the same cohort. Of the subset of genes we analyzed, only the Trpc5 ion channel expression reached statistical significance and only in male responder mice. Nonetheless, there were trends that support involvement of the gonadotropin hormone receptor (Gnrhr), pituitary glycoprotein hormones (Lhb, Tshb, Cga), and Kcnk12 ion channel. For all these genes, the difference was predominantly in male, not female mice. The variability within the same cohorts indicates that a single gene is not likely to be sufficient or required for the responder phenotype. Together, the RNA-seq and qPCR results suggest that multiple genes determine the PACAP responder phenotype, which agrees with the complex inheritance pattern.
Further studies will be needed to identify and confirm the genes responsible for susceptibility to PACAP induction of light aversion.

When compared with PACAP-38, the injection of PACAP-27 only caused transient light aversion. While PACAP-27 and PACAP-38 have not been directly compared in humans, PACAP-27 caused fewer migraine-like attacks (55\%; Ghanizada et al., 2020) than PACAP-38 (91\%; Schytz et al., 2009). Because there are conflicting reports on the relative stability of the two PACAP isoforms (Bourgault et al., 2008), we cannot rule out a pharmacokinetic explanation. However, another possible explanation is that PACAP-38, but not PACAP-27, acts by mast cell degranulation, which was shown for dilation of the middle meningeal artery (Bhatt et al., 2014). In fact, only PACAP-38 can degranulate mast cells and acts via the orphan MrgB3 receptor (Pedersen et al., 2019). Studies exploring the role of MrgB3 may give insights to how PACAP-38 evokes symptoms of migraine in mice and people.

We found a trend, albeit not statistically significant, that PACAP had a greater effect in male compared with female mice, which was consistent with there being a lower percentage of nonresponders among male mice. The reason for this male bias is not known, but might reflect the difference in actions on neutrophils. PACAP-38 can enhance inflammatory and chemotactic markers in neutrophils (Kinhult et al., 2002; Harfi et al., 2004), 
A

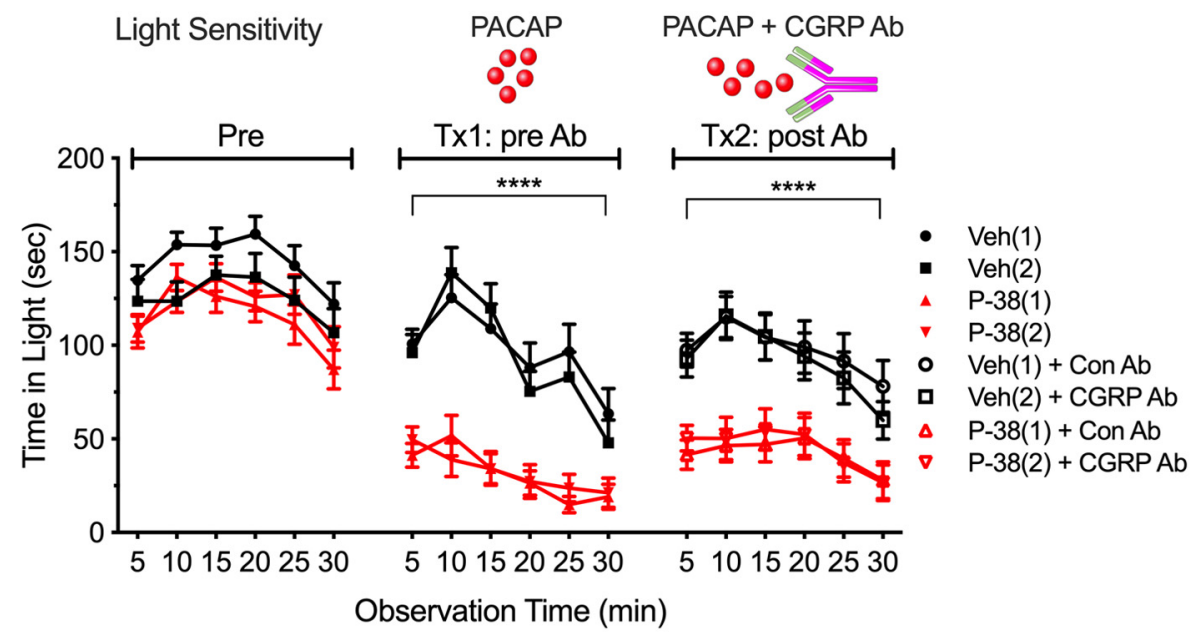

B

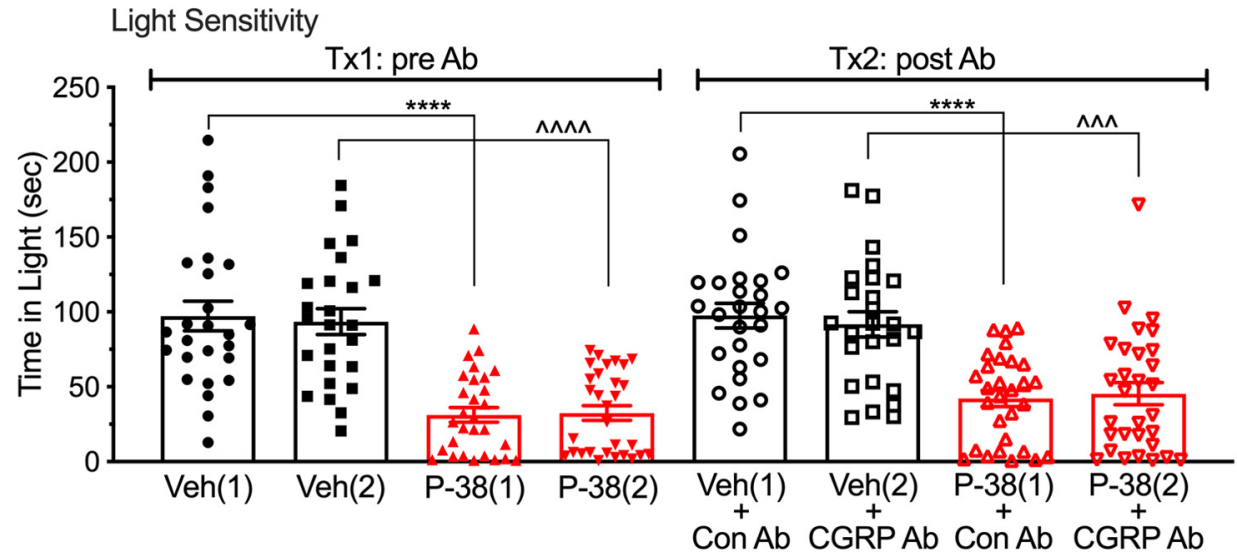

Figure 9. Anti-CGRP antibody does not inhibit PACAP-induced light aversion. $A$, Male and female mice were divided into four groups, two that would eventually get vehicle and two that would get PACAP. After a baseline pre-exposure (Pre), but before antibody treatments, mice were treated (Tx1: pre Ab) with vehicle [Veh(1), $n=26 ;$ Veh(2), $n=25]$ or PACAP-38 [0.3 mg/kg; $\mathrm{P}-38(1), n=29 ; \mathrm{P}-38(2), n=30]$. Three days after Tx1 mice were given an injection of control antibody (Con Ab) or anti-CGRP antibody (CGRP Ab), then $24 \mathrm{~h}$ later, mice were treated with vehicle or PACAP again (Tx2: post Ab). Mean ( \pm SEM) time spent in the light compartment every 5 min over a 30 min period is shown. $\boldsymbol{B}$, Data for individual mice from each treatment day are shown as the mean time ( \pm SEM) in light per $5 \mathrm{~min}$ interval. Statistics are described in Table 1. For motility, see Extended Data Figure 9-1.

and neutrophils are reportedly higher in males compared with females during acute inflammation (Kay et al., 2015). Neutrophil recruitment and activation may be relevant given reports of increased neutrophil/lymphocyte ratios during migraine (Karabulut et al., 2016).

The inability of the anti-CGRP and anti-PACAP antibodies to inhibit light aversion induced by the other peptide suggests that these peptides can act independently of each other in the periphery. The possibility of sequential or dependent pathways was raised by the similar properties (Kaiser and Russo, 2013), coexpression in trigeminal ganglia neurons (Eftekhari et al., 2015), and PACAP-38 causing CGRP release in the trigeminal nucleus caudalis (although not from the dura or ganglia; Jansen-Olesen et al., 2014). Against that hypothesis, a recent clinical study did not detect increased CGRP levels after PACAP-38 infusion (Guo et al., 2017). Furthermore, a migraine trigger (nitroglycerin) increased the number of PACAP-responsive neurons in mouse trigeminal ganglia by a mechanism independent of CGRP, while in contrast, the parallel increase in CGRP-responsive neurons required CGRP (Guo et al., 2021). However, a caveat of our studies is that light aversion was induced by exogenous peptides, which may supersede the release of endogenous CGRP or PACAP, so it is possible that both peptides may act in concert; hence, the two models (independent and dependent) are not mutually exclusive.
We propose that in the periphery CGRP and PACAP act by distinct, parallel paths that may converge downstream of their receptors. Both CGRP and PACAP receptors are known to be $G_{s}$ coupled and to activate CAMP-dependent and MAP kinase pathways (Hamelink et al., 2002; Zhang et al., 2007; Walker et al., 2010; Woolley et al., 2017). Thus, both receptors might activate similar intracellular signaling pathways that could lead to a host of cellular events, ranging from ion channel activation to mast cell degranulation. Potential cellular targets relevant to migraine are most likely in the meninges and trigeminal ganglia, where numerous cell types express both CGRP and PACAP receptors (Vaudry et al., 2009; Eftekhari et al., 2015; Edvinsson et al., 2018; Messlinger, 2018). CGRP and PACAP actions on these cells could potentially activate similar intracellular signals that lead to peripheral sensitization of the trigeminal system.

The efficacy of the humanized anti-PACAP antibody to block PACAP-induced light aversion in mice supports the potential use of this antibody to attenuate or prevent migraine in patients. An alternative approach to ligand-blocking antibodies is to target PACAP receptors (VPAC1, VPAC2, PAC1; Rubio-Beltran et al., 2018). Initial focus has been on the PAC1 receptor, in part because it is highly selective to PACAP, while the other receptors are equally activated by VIP (Rubio-Beltran et al., 2018) and VIP failed to induce migraine in early studies (Hansen et al., 2006). However, a role for VPAC receptors in migraine pathology 
should not be discarded. We have shown that VIP can also induce light aversive behavior in mice if measured immediately after administration, consistent with its shorter half-life compared with PACAP (Mason et al., 2020). Importantly, prolonged VIP infusion has now been shown to cause delayed headache in people (Pellesi et al., 2020). Alternatively, it is possible that PACAP-38 involvement in migraine may be independent of the VPAC or PAC1 receptors. PACAP-38 can act in the trigeminal nucleus via a PAC1-independent mechanism (Jansen-Olesen et al., 2014), and the orphan receptor Mrgb3 can mediate PACAP actions on mast cells (Pedersen et al., 2019).

Beyond migraine, PACAP and its receptors have been reported to affect a myriad of neurologic, metabolic, and reproductive disorders (Denes et al., 2019; Liao et al., 2019). Interestingly, some of these conditions overlap with CGRP actions (Kaiser and Russo, 2013). Of note, SNPs spanning the PACAP and PAC1 genes have been associated with post-traumatic stress disorder, schizophrenia, and major depressive disorder (Hashimoto et al., 2007, 2010; Ressler et al., 2011), although SNPs in those genes were not observed in this study. Future studies targeting PACAP and its receptors are likely to shed light on PACAP actions not only in migraine but also in other neurologic disorders.

\section{References}

Aiyar N, Rand K, Elshourbagy NA, Zeng Z, Adamou JE, Bergsma DJ, Li Y (1996) A cDNA encoding the calcitonin gene-related peptide type 1 receptor. J Biol Chem 271:11325-11329.

Aldinger KA, Sokoloff G, Rosenberg DM, Palmer AA, Millen KJ (2009) Genetic variation and population substructure in outbred CD-1 mice: implications for genome-wide association studies. PLoS One 4:e4729.

Arimura A (1992) Pituitary adenylate cyclase activating polypeptide (PACAP): discovery and current status of research. RegulPept 37:287303.

Arimura A, Somogyvári-Vigh A, Miyata A, Mizuno K, Coy DH, Kitada C (1991) Tissue distribution of PACAP as determined by RIA: highly abundant in the rat brain and testes. Endocrinology 129:2787-2789.

Ashina H, Schytz HW, Ashina M (2019) CGRP in human models of migraine. Handb Exp Pharmacol 255:109-120.

Avona A, Burgos-Vega C, Burton MD, Akopian AN, Price TJ, Dussor G (2019) Dural calcitonin gene-related peptide produces female-specific responses in rodent migraine models. J Neurosci 39:4323-4331.

Bhatt DK, Gupta S, Olesen J, Jansen-Olesen I (2014) PACAP-38 infusion causes sustained vasodilation of the middle meningeal artery in the rat: possible involvement of mast cells. Cephalalgia 34:877-886.

Bichet D, Blin S, Feliciangeli S, Chatelain FC, Bobak N, Lesage F (2015) Silent but not dumb: how cellular trafficking and pore gating modulate expression of TWIK1 and THIK2. Pflugers Arch 467:1121-1131.

Bohn KJ, Li B, Huang X, Mason BN, Wattiez AS, Kuburas A, Walker CS, Yang P, Yu J, Heinz BA, Johnson KW, Russo AF (2017) CGRP receptor activity in mice with global expression of human receptor activity modifying protein 1. Br J Pharmacol 174:1826-1840.

Boules M, Li Z, Smith K, Fredrickson P, Richelson E (2013) Diverse roles of neurotensin agonists in the central nervous system. Front Endocrinol (Lausanne) 4:36.

Bourgault S, Vaudry D, Botia B, Couvineau A, Laburthe M, Vaudry H, Fournier A (2008) Novel stable PACAP analogs with potent activity towards the PAC1 receptor. Peptides 29:919-932.

Brouard J-S, Schenkel F, Marete A, Bissonnette N (2019) The GATK joint genotyping workflow is appropriate for calling variants in RNA-seq experiments. J Anim Sci Biotechnol 10:44.

Cingolani P, Platts A, Wang LL, Coon M, Nguyen T, Wang L, Land SJ, Lu X, Ruden DM (2012) A program for annotating and predicting the effects of single nucleotide polymorphisms, SnpEff: SNPs in the genome of Drosophila melanogaster strain w1118; iso-2; iso-3. Fly (Austin) 6:80-92.

Cottrell GS (2019) CGRP receptor signalling pathways.Handb Exp Pharmacol 255:37-64.
Denes V, Geck P, Mester A, Gabriel R (2019) Pituitary adenylate cyclase-activating polypeptide: 30 years in research spotlight and 600 million years in service. J Clin Med 8:1488.

Deng X, Wang D, Wang S, Wang H, Zhou H (2018a) Identification of key genes and pathways involved in response to pain in goat and sheep by transcriptome sequencing. Biol Res 51:25.

Deng Y, Huang J, Zhang H, Zhu X, Gong Q (2018b) Association of expression of DRD2 rs1800497 polymorphism with migraine risk in Han Chinese individuals. J Pain Res 11:763-769.

Digre KB, Brennan KC (2012) Shedding light on photophobia. J Neuroophthalmol 32:68-81.

Dobin A, Gingeras TR (2015) Mapping RNA-seq reads with STAR. CurrProtoc Bioinformatics 51:11.14.1-11.14.19.

Dobner PR (2006) Neurotensin and pain modulation. Peptides 27:24052414.

Drahushuk K, Connell TD, Higgins D (2002) Pituitary adenylate cyclase-activating polypeptide and vasoactive intestinal peptide inhibit dendritic growth in cultured sympathetic neurons. J Neurosci 22:6560-6569.

Dussor G, Boyd JT, Akopian AN (2018) Pituitary hormones and orofacial pain. Front IntegrNeurosci 12:42.

Edvinsson L (2019) Role of CGRP in migraine. Handb Exp Pharmacol 255:121130.

Edvinsson L, Tajti J, Szalárdy L, Vécsei L (2018) PACAP and its role in primary headaches. J Headache Pain 19:21.

Eftekhari S, Salvatore CA, Johansson S, Chen TB, Zeng Z, Edvinsson L (2015) Localization of CGRP, CGRP receptor, PACAP and glutamate in trigeminal ganglion. Relation to the blood-brain barrier. Brain Res 1600:93-109.

Eneman B, Freson K, van den Heuvel L, van Hoyweghen E, Collard L, VandeWalle J, van Geet C, Levtchenko E (2015) Pituitary adenylate cyclaseactivating polypeptide deficiency associated with increased platelet count and aggregability in nephrotic syndrome. J ThrombHaemost 13:755-767.

Frederiksen SD, Warfvinge K, Ohlsson L, Edvinsson L (2018) Expression of pituitary adenylate cyclase-activating peptide, calcitonin gene-related peptide and headache targets in the trigeminal ganglia of rats and humans. Neuroscience 393:319-332.

Freson K, Hashimoto H, Thys C, Wittevrongel C, Danloy S, Morita Y, Shintani N, Tomiyama Y, Vermylen J, Hoylaerts MF, Baba A, Van Geet C (2004) The pituitary adenylate cyclase-activating polypeptide is a physiological inhibitor of platelet activation. J Clin Invest 113:905-912.

GBD 2016 Headache Collaborators (2018) Global, regional, and national burden of migraine and tension-type headache, 1990-2016: a systematic analysis for the Global Burden of Disease Study 2016. Lancet Neurol 17:954-976.

Ghanizada H, Al-Karagholi MA, Arngrim N, Olesen J, Ashina M (2020) PACAP27 induces migraine-like attacks in migraine patients. Cephalalgia 40:57-67.

Goadsby PJ, Edvinsson L (1993) The trigeminovascular system and migraine: studies characterizing cerebrovascular and neuropeptide changes seen in humans and cats. Ann Neurol 33:48-56.

Goadsby PJ, Holland PR, Martins-Oliveira M, Hoffmann J, Schankin C, Akerman S (2017) Pathophysiology of migraine: a disorder of sensory processing. Physiol Rev 97:553-622.

Gormley P, Anttila V, Winsvold BS, Palta P, Esko T, Pers TH, Farh K-H, Cuenca-Leon E, Muona M, Furlotte NA, Kurth T, Ingason A, McMahon G, Ligthart L, Terwindt GM, Kallela M, Freilinger TM, Ran C, Gordon SG, Stam AH, et al. (2016) Meta-analysis of 375,000 individuals identifies 38 susceptibility loci for migraine. Nat Genet 48:856-866.

Guo S, Vollesen AL, Hansen YB, Frandsen E, Andersen MR, Amin FM, Fahrenkrug J, Olesen J, Ashina M (2017) Part II: biochemical changes after pituitary adenylate cyclase-activating polypeptide-38 infusion in migraine patients. Cephalalgia 37:136-147.

Guo Z, Czerpaniak K, Zhang J, Cao YQ (2021) Increase in trigeminal ganglion neurons that respond to both CGRP and PACAP in mouse models of chronic migraine and post-traumatic headache. Pain 162:1483-1499.

Hamelink C, Lee HW, Chen Y, Grimaldi M, Eiden LE (2002) Coincident elevation of cAMP and calcium influx by PACAP-27 synergistically regulates vasoactive intestinal polypeptide gene transcription through a novel PKA-independent signaling pathway. J Neurosci 22:5310-5320.

Hansen JM, Sitarz J, Birk S, Rahmann AM, Oturai PS, Fahrenkrug J, Olesen J, Ashina M (2006) Vasoactive intestinal polypeptide evokes only a minimal headache in healthy volunteers. Cephalalgia 26:992-1003. 
Harfi I, D'Hondt S, Corazza F, Sariban E (2004) Regulation of human polymorphonuclear leukocytes functions by the neuropeptide pituitary adenylate cyclase-activating polypeptide after activation of MAPKs. J Immunol 173:4154-4163.

Harmar AJ, Fahrenkrug J, Gozes I, Laburthe M, May V, Pisegna JR, Vaudry D, Vaudry H, Waschek JA, Said SI (2012) Pharmacology and functions of receptors for vasoactive intestinal peptide and pituitary adenylate cyclase-activating polypeptide: IUPHAR review 1. Br J Pharmacol 166: 4-17.

Hashimoto H, Shintani N, Baba A (2006) New insights into the central PACAPergic system from the phenotypes in PACAP- and PACAP receptor-knockout mice. Ann N Y Acad Sci 1070:75-89.

Hashimoto R, Hashimoto H, Shintani N, Chiba S, Hattori S, Okada T, Nakajima M, Tanaka K, Kawagishi N, Nemoto K, Mori T, Ohnishi T, Noguchi H, Hori H, Suzuki T, Iwata N, Ozaki N, Nakabayashi T, Saitoh O, Kosuga A, et al. (2007) Pituitary adenylate cyclase-activating polypeptide is associated with schizophrenia. Mol Psychiatry 12:1026-1032.

Hashimoto R, Hashimoto H, Shintani N, Ohi K, Hori H, Saitoh O, Kosuga A, Tatsumi M, Iwata N, Ozaki N, Kamijima K, Baba A, Takeda M, Kunugi H (2010) Possible association between the pituitary adenylate cyclase-activating polypeptide (PACAP) gene and major depressive disorder. Neurosci Lett 468:300-302.

Hirabayashi T, Nakamachi T, Shioda S (2018) Discovery of PACAP and its receptors in the brain. J Headache Pain 19:28.

Jansen-Olesen I, Baun M, Amrutkar DV, Ramachandran R, Christophersen DV, Olesen J (2014) PACAP-38 but not VIP induces release of CGRP from trigeminal nucleus caudalis via a receptor distinct from the $\mathrm{PAC} 1$ receptor. Neuropeptides 48:53-64.

Jeong H, Moye LS, Southey BR, Hernandez AG, Dripps I, Romanova EV, Rubakhin SS, Sweedler JV, Pradhan AA, Rodriguez-Zas SL (2018) Gene network dysregulation in the trigeminal ganglia and nucleus accumbens of a model of chronic migraine-associated hyperalgesia. Front Syst Neurosci 12:63.

Kaiser EA, Russo AF (2013) CGRP and migraine: could PACAP play a role too?Neuropeptides 47:451-461.

Kaiser EA, Kuburas A, Recober A, Russo AF (2012) Modulation of CGRPinduced light aversion in wild-type mice by a $5-\mathrm{HT}(1 \mathrm{~B} / \mathrm{D})$ agonist. J Neurosci 32:15439-15449.

Kamburov A, Stelzl U, Lehrach H, Herwig R (2013) The ConsensusPathDB interaction database: 2013 update. Nucleic Acids Res 41:D793-D800.

Karabulut KU, Egercioglu TU, Uyar M, Ucar Y (2016) The change of neutrophils/lymphocytes ratio in migraine attacks: a case-controlled study. Ann Med Surg (Lond) 10:52-56.

Kay E, Gomez-Garcia L, Woodfin A, Scotland RS, Whiteford JR (2015) Sexual dimorphisms in leukocyte trafficking in a mouse peritonitis model. J Leukoc Biol 98:805-817.

Khan S, Schoenen J, Ashina M (2014) Sphenopalatine ganglion neuromodulation in migraine: what is the rationale? Cephalalgia 34:382-391.

Kinhult J, Egesten A, Uddman R, Cardell LO (2002) PACAP enhances the expression of CD11b, CD66b and CD63 in human neutrophils. Peptides 23:1735-1739.

Lafrenière RG, Cader MZ, Poulin JF, Andres-Enguix I, Simoneau M, Gupta N, Boisvert K, Lafrenière F, McLaughlan S, Dubé MP, Marcinkiewicz MM, Ramagopalan S, Ansorge O, Brais B, Sequeiros J, Pereira-Monteiro JM, Griffiths LR, Tucker SJ, Ebers G, Rouleau GA (2010) A dominantnegative mutation in the TRESK potassium channel is linked to familial migraine with aura. Nat Med 16:1157-1160.

Lassen LH, Haderslev PA, Jacobsen VB, Iversen HK, Sperling B, Olesen J (2002) CGRP may play a causative role in migraine. Cephalalgia 22:5461.

Lemaire I (1988) Neurotensin enhances IL-1 production by activated alveolar macrophages. J Immunol 140:2983-2988.

Li S, Grinevich V, Fournier A, Pelletier G (1996) Effects of pituitary adenylate cyclase-activating polypeptide (PACAP) on gonadotropin-releasing hormone and somatostatin gene expression in the rat brain. Brain Res Mol Brain Res 41:157-162.

Liao C, de Molliens MP, Schneebeli ST, Brewer M, Song G, Chatenet D, Braas KM, May V, Li J (2019) Targeting the PAC1 receptor for neurological and metabolic disorders. Curr Top Med Chem 19:1399-1417.

Lippert C, Listgarten J, Liu Y, Kadie CM, Davidson RI, Heckerman D (2011) FaST linear mixed models for genome-wide association studies. Nat Methods 8:833-835.
Liu YY, Jiao ZY, Li W, Tian Q (2017) PI3K/AKT signaling pathway activation in a rat model of migraine. Mol Med Rep 16:4849-4854.

Love MI, Huber W, Anders S (2014) Moderated estimation of fold change and dispersion for RNA-seq data with DESeq2. Genome Biol 15:550.

Manteniotis S, Lehmann R, Flegel C, Vogel F, Hofreuter A, Schreiner BS, Altmüller J, Becker C, Schöbel N, Hatt H, Gisselmann G (2013) Comprehensive RNA-Seq expression analysis of sensory ganglia with a focus on ion channels and GPCRs in trigeminal ganglia. PLoS One 8: e79523.

Markovics A, Kormos V, Gaszner B, Lashgarara A, Szoke E, Sandor K, Szabadfi K, Tuka B, Tajti J, Szolcsanyi J, Pinter E, Hashimoto H, Kun J, Reglodi D, Helyes Z (2012) Pituitary adenylate cyclase-activating polypeptide plays a key role in nitroglycerol-induced trigeminovascular activation in mice. Neurobiol Dis 45:633-644.

Marsh B, Acosta C, Djouhri L, Lawson SN (2012) Leak K ${ }^{+}$channel mRNAs in dorsal root ganglia: relation to inflammation and spontaneous pain behaviour. Mol Cell Neurosci 49:375-386.

Mason BN, Kaiser EA, Kuburas A, Loomis MM, Latham JA, GarciaMartinez LF, Russo AF (2017) Induction of migraine-like photophobic behavior in mice by both peripheral and central CGRP mechanisms. J Neurosci 37:204-216.

Mason BN, Wattiez AS, Balcziak LK, Kuburas A, Kutschke WJ, Russo AF (2020) Vascular actions of peripheral CGRP in migraine-like photophobia in mice. Cephalalgia 40:1585-1604.

McKenna A, Hanna M, Banks E, Sivachenko A, Cibulskis K, Kernytsky A, Garimella K, Altshuler D, Gabriel S, Daly M, DePristo MA (2010) The Genome Analysis Toolkit: a MapReduce framework for analyzing nextgeneration DNA sequencing data. Genome Res 20:1297-1303.

Messlinger K (2018) The big CGRP flood - sources, sinks and signalling sites in the trigeminovascular system. J Headache Pain 19:22.

Miyata A, Arimura A, Dahl RR, Minamino N, Uehara A, Jiang L, Culler MD, Coy DH (1989) Isolation of a novel 38 residue-hypothalamic polypeptide which stimulates adenylate cyclase in pituitary cells. BiochemBiophys Res Commun 164:567-574.

Miyata A, Jiang L, Dahl RD, Kitada C, Kubo K, Fujino M, Minamino N, Arimura A (1990) Isolation of a neuropeptide corresponding to the Nterminal 27 residues of the pituitary adenylate cyclase activating polypeptide with 38 residues (PACAP38). BiochemBiophys Res Commun 170:643-648.

Moldovan Loomis C, Dutzar B, Ojala EW, Hendrix L, Karasek C, ScalleyKim M, Mulligan J, Fan P, Billgren J, Rubin V, Boshaw H, Kwon G, Marzolf S, Stewart E, Jurchen D, Pederson SM, Perrino McCulloch L, Baker B, Cady RK, Latham JA, et al. (2019) Pharmacologic characterization of ALD1910, a potent humanized monoclonal antibody against the pituitary adenylate cyclase-activating peptide. J Pharmacol Exp Ther 369:26-36.

Moulton EA, Becerra L, Borsook D (2009) An fMRI case report of photophobia: activation of the trigeminal nociceptive pathway. Pain 145:358-363.

Nilsson SF, De Neef P, Robberecht P, Christophe J (1994) Characterization of ocular receptors for pituitary adenylate cyclase activating polypeptide (PACAP) and their coupling to adenylate cyclase. Exp Eye Res 58:459467.

Noseda R, Burstein R (2013) Migraine pathophysiology: anatomy of the trigeminovascular pathway and associated neurological symptoms, cortical spreading depression, sensitization and modulation of pain. Pain 154: S44-S53.

Patil M, Belugin S, Mecklenburg J, Wangzhou A, Paige C, Barba-Escobedo PA, Boyd JT, Goffin V, Grattan D, Boehm U, Dussor G, Price TJ, Akopian AN (2019) Prolactin regulates pain responses via a female-selective nociceptor-specific mechanism. iScience 20:449-465.

Pedersen SH, la Cour SH, Calloe K, Hauser F, Olesen J, Klaerke DA, JansenOlesen I (2019) PACAP-38 and PACAP(6-38) degranulate rat meningeal mast cells via the orphan MrgB3-receptor. Front Cell Neurosci 13:114.

Pellesi L, Al-Karagholi MA, Chaudhry BA, Lopez CL, Snellman J, Hannibal J, Amin FM, Ashina M (2020) Two-hour infusion of vasoactive intestinal polypeptide induces delayed headache and extracranial vasodilation in healthy volunteers. Cephalalgia 40:1212-1223.

Pertea M, Kim D, Pertea GM, Leek JT, Salzberg SL (2016) Transcript-level expression analysis of RNA-seq experiments with HISAT, StringTie and Ballgown. Nat Protoc 11:1650-1667.

Puig-Parellada P, Planas JM, Giménez J, Obach J (1993) Migraine: implication of arachidonic acid metabolites. Prostaglandins Leukot Essent Fatty Acids 49:537-547. 
Ramón C, Cernuda-Morollón E, Pascual J (2017) Calcitonin gene-related peptide in peripheral blood as a biomarker for migraine. CurrOpin Neurol 30:281-286.

Ressler KJ, Mercer KB, Bradley B, Jovanovic T, Mahan A, Kerley K, Norrholm SD, Kilaru V, Smith AK, Myers AJ, Ramirez M, Engel A, Hammack SE, Toufexis D, Braas KM, Binder EB, May V (2011) Posttraumatic stress disorder is associated with PACAP and the PAC1 receptor. Nature 470:492-497.

Rubio-Beltran E, Correnti E, Deen M, Kamm K, Kelderman T, Papetti L, Vigneri S, MaassenVanDenBrink A, Edvinsson L (2018) PACAP38 and PAC1 receptor blockade: a new target for headache? J Headache Pain 19:64.

Russo AF (2015) Calcitonin gene-related peptide (CGRP): a new target for migraine. Annu Rev PharmacolToxicol 55:533-552.

Russo AF (2017) Overview of neuropeptides: awakening the senses? Headache 57 [Suppl 2]:37-46.

Russo AF, Kuburas A, Kaiser EA, Raddant AC, Recober A (2009) A potential preclinical migraine model: CGRP-sensitized mice. Mol Cell Pharmacol $1: 264-270$

Sadler KE, Moehring F, Shiers SI, Laskowski LJ, Mikesell AR, Plautz ZR, Brezinski AN, Mecca CH, Dussor G, Price TJ, McCorvy JD, Stucky CL (2021) Transient receptor potential canonical 5 (TRPC5) mediates inflammatory mechanical and spontaneous pain. Sci Transl Med, in press.

Schoenen J (2015) Sphenopalatine ganglion stimulation in neurovascular headaches. Prog Neurol Surg 29:106-116.

Schytz HW, Birk S, Wienecke T, Kruuse C, Olesen J, Ashina M (2009) PACAP38 induces migraine-like attacks in patients with migraine without aura. Brain 132:16-25.

Scuteri D, Adornetto A, Rombolà L, Naturale MD, Morrone LA, Bagetta G, Tonin P, Corasaniti MT (2019) New trends in migraine pharmacology: targeting calcitonin gene-related peptide (CGRP) with monoclonal antibodies. Front Pharmacol 10:363.

Shen B, Wong CO, Lau OC, Woo T, Bai S, Huang Y, Yao X (2015) Plasma membrane mechanical stress activates TRPC5 channels. PLoS One 10: e0122227.

Soneson C, Love M, Robinson M (2015) Differential analyses for RNA-seq: transcript-level estimates improve gene-level inferences [version 1; peer review: 2 approved. F1000Res 4:1521.

Song K, Li L, Zhang G (2016) Coverage recommendation for genotyping analysis of highly heterologous species using next-generation sequencing technology. Sci Rep 6:35736.

Steinberg A, Frederiksen SD, Blixt FW, Warfvinge K, Edvinsson L (2016) Expression of messenger molecules and receptors in rat and human sphenopalatine ganglion indicating therapeutic targets. J Headache Pain 17:78.

Stone LS, Molliver DC (2009) In search of analgesia: emerging roles of GPCRs in pain. Mol Interv 9:234-251.

Theoharides TC, Donelan J, Kandere-Grzybowska K, Konstantinidou A (2005) The role of mast cells in migraine pathophysiology. Brain Res Brain Res Rev 49:65-76.

Tringali G, Navarra P (2019) Anti-CGRP and anti-CGRP receptor monoclonal antibodies as antimigraine agents. Potential differences in safety profile postulated on a pathophysiological basis. Peptides 116:16-21.

Tuka B, Helyes Z, Markovics A, Bagoly T, Szolcsányi J, Szabó N, Tóth E, Kincses ZT, Vécsei L, Tajti J (2013) Alterations in PACAP-38-like immunoreactivity in the plasma during ictal and interictal periods of migraine patients. Cephalalgia 33:1085-1095.

Uddman R, Tajti J, Möller S, Sundler F, Edvinsson L (1999) Neuronal messengers and peptide receptors in the human sphenopalatine and otic ganglia. Brain Res 826:193-199.

Umatani C, Oka Y (2019) Multiple functions of non-hypophysiotropic gonadotropin releasing hormone neurons in vertebrates. Zoological Lett 5:23.

Vaudry D, Gonzalez BJ, Basille M, Yon L, Fournier A, Vaudry H (2000) Pituitary adenylate cyclase-activating polypeptide and its receptors: from structure to functions. Pharmacol Rev 52:269-324.

Vaudry D, Falluel-Morel A, Bourgault S, Basille M, Burel D, Wurtz O, Fournier A, Chow BK, Hashimoto H, Galas L, Vaudry H (2009) Pituitary adenylate cyclase-activating polypeptide and its receptors: 20 years after the discovery. Pharmacol Rev 61:283-357.

Walder RY, Wattiez AS, White SR, Marquez de Prado B, Hamity MV, Hammond DL (2014) Validation of four reference genes for quantitative mRNA expression studies in a rat model of inflammatory injury. Mol Pain 10:55.

Walker CS, Conner AC, Poyner DR, Hay DL (2010) Regulation of signal transduction by calcitonin gene-related peptide receptors. Trends Pharmacol Sci 31:476-483.

Woolley MJ, Reynolds CA, Simms J, Walker CS, Mobarec JC, Garelja ML, Conner AC, Poyner DR, Hay DL (2017) Receptor activity-modifying protein dependent and independent activation mechanisms in the coupling of calcitonin gene-related peptide and adrenomedullin receptors to Gs. BiochemPharmacol 142:96-110.

Zagami AS, Edvinsson L, Goadsby PJ (2014) Pituitary adenylate cyclase activating polypeptide and migraine. Ann Clin Transl Neurol 1:1036-1040.

Zhang Z, Winborn CS, Marquez de Prado B, Russo AF (2007) Sensitization of calcitonin gene-related peptide receptors by receptor activity-modifying protein-1 in the trigeminal ganglion. J Neurosci 27:2693-2703. 